University of Wollongong

Research Online

Australian Institute for Innovative Materials -

Papers

Australian Institute for Innovative Materials

$1-1-2018$

\title{
Active-Site-Enriched Iron-Doped Nickel/Cobalt Hydroxide Nanosheets for Enhanced Oxygen Evolution Reaction
}

Qian Zhou

University of Wollongong, qz704@uowmail.edu.au

Yaping Chen

University of Wollongong, yc463@uowmail.edu.au

Guoqiang Zhao

University of Wollongong, gz815@uowmail.edu.au

Yue Lin

University of Science and Technology of China

Zhenwei Yu

University of Wollongong, zy139@uowmail.edu.au

See next page for additional authors

Follow this and additional works at: https://ro.uow.edu.au/aiimpapers

Part of the Engineering Commons, and the Physical Sciences and Mathematics Commons

Research Online is the open access institutional repository for the University of Wollongong. For further information contact the UOW Library: research-pubs@uow.edu.au 


\title{
Active-Site-Enriched Iron-Doped Nickel/Cobalt Hydroxide Nanosheets for Enhanced Oxygen Evolution Reaction
}

\begin{abstract}
Highly active, durable, and inexpensive nanostructured catalysts are crucial for achieving efficient and economical electrochemical water splitting. However, developing efficient approaches to further improve the catalytic ability of the well-defined nanostructured catalysts is still a big challenge. Herein, we report a facile and universal cation-exchange process for synthesizing Fe-doped $\mathrm{Ni}(\mathrm{OH}) 2$ and $\mathrm{Co}(\mathrm{OH}) 2$ nanosheets with enriched active sites toward enhanced oxygen evolution reaction (OER). In comparison with typical NiFe layered double hydroxide (LDH) nanosteets prepared by the conventional one-pot method, Fe-doped $\mathrm{Ni}(\mathrm{OH}) 2$ nanosheets evolving from $\mathrm{Ni}(\mathrm{OH}) 2$ via an $\mathrm{Fe} 3+/ \mathrm{Ni} 2+$ cation-exchange process possess nanoporous surfaces with abundant defects. Accordingly, Fe-doped $\mathrm{Ni}(\mathrm{OH}) 2$ nanosheets exhibit higher electrochemical active surface area (ECSA) and improved surface wettability in comparison to NiFe LDH nanosheets and deliver significantly enhanced catalytic activity over NiFe LDH. Specifically, a low overpotential of only $245 \mathrm{mV}$ is required to reach a current density of $10 \mathrm{~mA} \mathrm{~cm}-2$ for $\mathrm{Ni} 0.83 \mathrm{Fe} 0.17(\mathrm{OH}) 2$ nanosheets with a low Tafel slope of $61 \mathrm{mV}$ dec-1, which is greatly decreased in comparison with those of NiFe LDH ( $310 \mathrm{mV}$ and $78 \mathrm{mV}$ dec-1). Additionally, this cation-exchange process is successfully extended to prepare Fe-doped $\mathrm{Co}(\mathrm{OH}) 2$ nanosheets with improved catalytic activity for oxygen evolution. The results suggest that this cation-exchange process should have great potential in the rational design of defect-enriched catalysts toward high-performance electrocatalysis.
\end{abstract}

\section{Keywords}

hydroxide, nanosheets, enhanced, evolution, oxygen, reaction, active-site-enriched, iron-doped, nickel/ cobalt

\section{Disciplines}

Engineering | Physical Sciences and Mathematics

\section{Publication Details}

Zhou, Q., Chen, Y., Zhao, G., Lin, Y., Yu, Z., Xu, X., Wang, X., Liu, H. Kun., Sun, W. \& Dou, S. Xue. (2018). Active-Site-Enriched Iron-Doped Nickel/Cobalt Hydroxide Nanosheets for Enhanced Oxygen Evolution Reaction. ACS Catalysis, 8 5382-5390.

\section{Authors}

Qian Zhou, Yaping Chen, Guoqiang Zhao, Yue Lin, Zhenwei Yu, Xun Xu, Xiaolin Wang, Hua-Kun Liu, Wenping Sun, and Shi Xue Dou 


\section{Active Site-Enriched Iron-Doped Nickel/Cobalt}

\section{Hydroxide Nanosheets for Enhanced Oxygen}

\section{Evolution Reaction}

Qian Zhou ${ }^{a}$, Yaping Chen ${ }^{a}$, Guoqiang Zhao ${ }^{a}$, Yue Lin $^{b, *}$, Zhenwei Yu ${ }^{a}$, Xun Xu ${ }^{a, *}$, Xiaolin Wang ${ }^{a}$, Hua Kun Liu ${ }^{a}$, Wenping Sun ${ }^{a,}$, Shi Xue Dou ${ }^{a}$

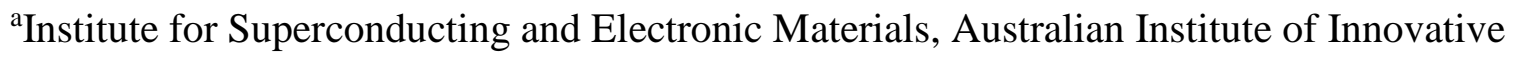

Materials, University of Wollongong, Wollongong, NSW 2522, Australia

Email: xun@uow.edu.au; wenping@uow.edu.au

${ }^{b}$ Hefei National Laboratory for Physical Sciences at the Microscale, University of Science and

Technology of China, Hefei, Anhui 230026, P. R. China

Email: linyue@ustc.edu.cn

KEYWORDS: Cation exchange, $\mathrm{Ni}(\mathrm{OH})_{2}$ nanosheets, wettability, oxygen evolution reaction, electrocatalysis 
ABSTRACT: Highly active, durable and inexpensive nanostructured catalysts are crucial for achieving efficient and economical electrochemical water splitting. However, developing efficient approaches to further improve the catalytic ability of the well-defined nanostructured catalysts is still a big challenge. Herein, we report a facile and universal cation-exchange process for synthesizing Fe-doped $\mathrm{Ni}(\mathrm{OH})_{2}$ and $\mathrm{Co}(\mathrm{OH})_{2}$ nanosheets with enriched active sites towards enhanced oxygen evolution reaction (OER). Compared with typical NiFe layered double hydroxide (LDH) nanosteets prepared by the conventional one-pot method, Fe-doped $\mathrm{Ni}(\mathrm{OH})_{2}$ nanosheets evolving from $\mathrm{Ni}(\mathrm{OH})_{2}$ via $\mathrm{Fe}^{3+} / \mathrm{Ni}^{2+}$ cation-exchange process possess nanoporous surfaces with abundant defects. Accordingly, Fe-doped $\mathrm{Ni}(\mathrm{OH})_{2}$ nanosheets exhibit higher electrochemical active surface area (ECSA) and improved surface wettability than NiFe LDH nanosheets, and deliver significantly enhanced catalytic activity over NiFe LDH. Specifically, a low overpotential of only $245 \mathrm{mV}$ is required to reach a current density of $10 \mathrm{~mA} \mathrm{~cm}{ }^{-2}$ for $\mathrm{Ni}_{0.83} \mathrm{Fe}_{0.17}(\mathrm{OH})_{2}$ nanosheets with a low Tafel slope of $61 \mathrm{mV} \mathrm{dec}^{-1}$, which is greatly decreased as compared with that of $\mathrm{NiFe} \mathrm{LDH}\left(310 \mathrm{mV}\right.$ and $\left.78 \mathrm{mV} \mathrm{dec}^{-1}\right)$. Additionally, this cationexchange process is successfully extended to prepare Fe-doped $\mathrm{Co}(\mathrm{OH})_{2}$ nanosheets, which also exhibit better catalytic performance for oxygen evolution than that of pristine $\mathrm{Co}(\mathrm{OH})_{2}$. The results suggest that this cation-exchange process would have a great potential in rational design of defect-enriched catalysts toward high-performance electrocatalysis.

\section{INTRODUCTION}

Recently, oxygen evolution catalysis has drawn ever-increasing attention because it plays a critical role in a variety of energy conversion and storage devices, such as electrochemical water splitting, metal-air batteries, and so forth. ${ }^{1-3}$ However, it has to be noted that the oxygen 
evolution reaction (OER) kinetics is sluggish owing to the complicated four-electron transfer process, which is regarded as the bottleneck for electrochemical water splitting and metal-air batteries. ${ }^{4-7}$ Developing highly active catalysts is critical for achieving accelerated reaction kinetics. Recently, Ni/Co-based layered double hydroxides (LDHs) have demonstrated to be very promising OER catalysts due to their earth abundance, high electrocatalytic activity and good stability. ${ }^{8-11}$ In particular, NiFe $\mathrm{LDH}$, which can be considered as $\mathrm{Fe}^{3+}$ doped $\mathrm{Ni}(\mathrm{OH})_{2}$, has been extensively studied owing to its extraordinary electrocatalytic activity, ${ }^{12}$ and intensive research efforts have been made to further enhance the catalytic performance of NiFe LDH by tuning the chemical composition and/or engineering various nanostructures. ${ }^{10,12-17}$ It should be noted that most reports were focused on coupling NiFe LDH with conductive carbonaceous materials (e.g., graphene, carbon nanotubes). ${ }^{18-21}$ In this regard, the catalytic activity is basically enhanced by accelerated charge-transfer kinetics and some so-called synergistic effects. Little attention has been paid to enhancing the intrinsic activity and/or increasing active sites of NiFe LDH. For most transition metal-based 2D materials, the active sites are mainly located at the edge sites, and the oxidation reaction to generate catalytically active phase with high valence is hindered by the closed-packed basal planes in some degree. ${ }^{8,22}$ Hence, activating these basal planes is vital to further enhance the catalytic activity of nanostructured NiFe LDH. Recently, engineering various defects and nanopores in 2D electrocatalysts has been developed as effective strategies to activate the basal planes. ${ }^{23-26}$ For example, Xie et al. prepared ultrathin $\beta-\mathrm{Ni}(\mathrm{OH})_{2}$ nanomesh with abundant nanopores, leading to rich active sites on basal planes, thus exhibiting remarkable catalytic performance. ${ }^{24}$ And Ye et al. introduced abundant active sites on the surface of $\mathrm{MoS}_{2}$ by oxygen plasma exposure and hydrogen treatment, resulting in significant enhancement of hydrogen evolution activity. ${ }^{25}$ Besides, the nanoporous structure is also helpful to mass transfer 
and gas bubbles release. ${ }^{27}$ Currently, NiFe LDH is mainly synthesized by one-pot processes, mainly including homogeneous co-precipitation, ${ }^{12,}$ 19, 28-30 hydrothermal reaction, ${ }^{13-14,} 30$ and electrodeposition ${ }^{31-36}$. However, NiFe LDH synthesized by these methods endows close-packed basal planes, which considerably restrict the exposure of active sites.

Herein, a facile cation-exchange process is developed to synthesize Fe-doped $\mathrm{Ni}(\mathrm{OH})_{2}$ nanosheets with abundant active sites. The Fe-doped $\mathrm{Ni}(\mathrm{OH})_{2}$ nanosheets prepared by this cation-exchange process show substantially improved electrocatalytic performance than pristine $\mathrm{Ni}(\mathrm{OH})_{2}$ nanosheets and $\mathrm{NiFe} \mathrm{LDH}$ with similar ratio of $\mathrm{Ni} / \mathrm{Fe}$. Moreover, this cation-exchange process is successfully utilized to prepare highly active Fe-doped $\mathrm{Co}(\mathrm{OH})_{2}$ nanosheets. The results suggest that cation exchange is a very promising approach to engineer nanostructures with significantly enriched defects and active sites towards enhanced electrocatalysis.

\section{EXPERIMENT SECTION}

Synthesis of $\mathrm{Ni}(\mathrm{OH})_{2}$ and $\mathrm{Co}(\mathrm{OH})_{2}$ nanosheets. $\mathrm{Ni}(\mathrm{OH})_{2}$ nanosheets were synthesized by a modified solvothermal reaction method. ${ }^{37}$ For the synthesis of $\mathrm{Ni}(\mathrm{OH})_{2}$ nanosheets, 0.9 mmol nickel(II) nitrate hexahydrate and $1.8 \mathrm{mmol}$ urea were dissolved in a mixed solution of DI water (12 mL) and ethylene glycol (EG, $28 \mathrm{~mL}$ ). After stirring for 1h, the solution was transferred to a $50 \mathrm{~mL}$ Teflon-lined stainless steel autoclave for solvothermal reaction at $120^{\circ} \mathrm{C}$ for $12 \mathrm{~h}$. After cooling down to room temperature, the products were collected by centrifugation, washed with DI water and ethanol, and followed by drying at $60{ }^{\circ} \mathrm{C}$ in oven for $10 \mathrm{~h}$. For the synthesis of $\mathrm{Co}(\mathrm{OH})_{2}$ nanosheets, $\quad 0.9$ mmol cobalt(II) nitrate hexahydrate and 1.8 mmol hexamethylenetetramine (HMT) were dissolved in a mixed solution of DI water (16 mL) and EG 
(24 mL). Then, the solution was transferred to a $50 \mathrm{~mL}$ Teflon-lined stainless steel autoclave for solvothermal reaction at $120^{\circ} \mathrm{C}$ for $10 \mathrm{~h}$. The products were collected by centrifugation, washed with DI water and ethanol three times, and eventually dried at $60{ }^{\circ} \mathrm{C}$ in oven for $10 \mathrm{~h}$.

Synthesis of Fe-doped $\mathrm{Ni}(\mathrm{OH})_{2}$ nanosheets and Fe-doped $\mathrm{Co}(\mathrm{OH})_{2}$ nanosheets. Fe-doped $\mathrm{Ni}(\mathrm{OH})_{2}$ nanosheets were synthesized via the cation-exchange reaction. Firstly, $50 \mathrm{mg} \mathrm{Ni}(\mathrm{OH})_{2}$ nanosheets was added into $50 \mathrm{~mL}$ ethanol. The mixture was sonicated for $3 \mathrm{~h}$ and stirred for another $1 \mathrm{~h}$ to get a suspension. And then, anhydrous $\mathrm{FeCl}_{3}(5 \mathrm{mg}, 12.5 \mathrm{mg}$ or $20 \mathrm{mg}$ ) was added to the suspension, and was stirred at $50{ }^{\circ} \mathrm{C}$ for $12 \mathrm{~h}$ for sufficient cation-exchange reaction to eventually obtain Fe-doped $\mathrm{Ni}(\mathrm{OH})_{2}$ nanosheets. The Fe-doped $\mathrm{Ni}(\mathrm{OH})_{2}$ nanosheets were collected by centrifugation, washed with DI water and ethanol for three times, and eventually drying in oven at $60{ }^{\circ} \mathrm{C}$ for $10 \mathrm{~h}$. The $\mathrm{Ni} / \mathrm{Fe}$ ratio of $\mathrm{Fe}$-doped $\mathrm{Ni}(\mathrm{OH})_{2}$ nanosheets were measured by Inductively Coupled Plasma Mass Spectrometry (ICP-MS). The nominal composition was determined to be $\mathrm{Ni}_{0.97} \mathrm{Fe}_{0.03}(\mathrm{OH})_{2}, \mathrm{Ni}_{0.83} \mathrm{Fe}_{0.17}(\mathrm{OH})_{2}$, and $\mathrm{Ni}_{0.77} \mathrm{Fe}_{0.23}(\mathrm{OH})_{2}$ for the sample using 5, 12.5, and $20 \mathrm{mg} \mathrm{FeCl}$, respectively. The synthesis procedure of Fe-doped $\mathrm{Co}(\mathrm{OH})_{2}$ nanosheets was similar to the that of Fe-doped $\mathrm{Ni}(\mathrm{OH})_{2}$ nanosheets, while the precursor material is $\mathrm{Co}(\mathrm{OH})_{2}$ nanosheets rather than $\mathrm{Ni}(\mathrm{OH})_{2}$.

Synthesis of NiFe LDH nanosheets. The synthesis procedure of $\mathrm{Ni}_{0.85} \mathrm{Fe}_{0.15}(\mathrm{OH})_{2} \mathrm{LDH}$ nanosheets is similar to that of $\mathrm{Ni}(\mathrm{OH})_{2}$ nanosheets. $0.75 \mathrm{mmol}$ nickel(II) nitrate hexahydrate, $0.15 \mathrm{mmol}$ Iron(III) nitrate nonahydrate and $1.8 \mathrm{mmol}$ urea were dissolved in a mixed solvent of DI water $(12 \mathrm{~mL})$ and EG (28 mL). After stirring for $1 \mathrm{~h}$, the solution was transferred to a $50 \mathrm{~mL}$ Teflon-lined stainless steel autoclave for solvothermal reaction at $120^{\circ} \mathrm{C}$ for $12 \mathrm{~h}$. After cooling down to room temperature, the products were collected by centrifugation, washed with DI water and ethanol three times, and eventually dried in oven at $60^{\circ} \mathrm{C}$ for $10 \mathrm{~h}$. 
Physical Characterization. X-ray diffraction (XRD) patterns of the samples were measured by GBC Scientific Equipment LLC X-ray powder diffractometer $(\mathrm{Cu} \mathrm{K \alpha}, \lambda=1.54182 \AA)$. The morphology of the samples were acquired using JEM-2010 transmission electron microscope (TEM) with an acceleration voltage of $200 \mathrm{kV}$. High-angle annular dark field scanning transmission electron microscopy (HAADF-STEM) images were collected using a probecorrected JEOL ARM200F with an acceleration voltage of $200 \mathrm{kV}$. The elemental mapping was carried out by four symmetrical EDS signal detectors equipped on FEI Talos F200X. X-ray photoelectron spectroscopy (XPS) was acquired on a Thermo ESCALAB 250Xi instrument (Al $\mathrm{K} \alpha$ ). The ICP emission spectrum was conducted on a Perkin Elmer Optima 7300DV ICP emission spectroscope. Contact angles were measured on Dataphysics OCA15 with $1 \mu \mathrm{L} 1 \mathrm{M}$ $\mathrm{KOH}$ solution for each testing. Raman spectra were acquired using a Raman spectrometer (Lab RAM HR, Horiba Jobin Yvon SAS).

Electrochemical measurements. All electrochemical tests were performed in a standard three electrode system using a WaveDriver 20 electrochemistry workstation (Pine Research Instruments, US) at room temperature. Pt wire was used as the counter electrode and $\mathrm{Ag} / \mathrm{AgCl}$ (saturated $\mathrm{KCl}$ solution) was employed as the reference electrode. For preparation of the working electrode, $4.0 \mathrm{mg}$ catalyst was dispersed in $1 \mathrm{~mL}$ water-isopropanol mixed solution with volume ratio of 3:1 containing $30 \mu \mathrm{L}$ nafion solution ( $5 \mathrm{wt} \%$ ), and the above suspension was then sonicated for at least $1 \mathrm{~h}$ to obtain a homogeneous ink. $10 \mu \mathrm{L}$ of the catalyst ink was drop-cast onto a glassy carbon electrode (GCE) with diameter of $5 \mathrm{~mm}$, and the mass loading on GCE is $0.204 \mathrm{mg} \mathrm{cm}^{-2}$. Finally, the catalyst film was dried naturally in air. The potential data were converted to the potential vs. reversible hydrogen electrode (RHE) according to the equation $\mathrm{E}$ $(\mathrm{RHE})=\mathrm{E}(\mathrm{Ag} / \mathrm{AgCl})+0.059 \mathrm{PH}+0.197 \mathrm{~V}$. Linear sweep voltammetry (LSV) was conducted 
with a scan rate of $5 \mathrm{mV} \mathrm{s}^{-1}$ at the rotation speed of $1600 \mathrm{rpm}$. All LSV polarization curves were corrected with $90 \%$ iR-compensation. The double layer capacitance $\left(\mathrm{C}_{\mathrm{dl}}\right)$, which was used to roughly represent the electrochemical surface area (ECSA), was estimated by cyclic voltammetry (CV) at a potential window of 0.35-0.4 V (vs. $\mathrm{Ag} / \mathrm{AgCl})$ at scan rates of 40, 60, 80, 100, 120 and $140 \mathrm{mV} \mathrm{s}^{-1}$. $\mathrm{C}_{\mathrm{dl}}$ was obtained by plotting the $\Delta \mathrm{J}=\left(\mathrm{J}_{\mathrm{a}}-\mathrm{J}_{\mathrm{c}}\right)$ at $0.375 \mathrm{~V}(\mathrm{vs}$. Ag/AgCl) against the scan rate, and the linear slope is twice of the $\mathrm{C}_{\mathrm{dl}}$ value. The AC impedance spectra were performed with frequency ranging from $100 \mathrm{kHz}$ to $10 \mathrm{mHz}$ at $0.5 \mathrm{~V}$ (vs. $\mathrm{Ag} / \mathrm{AgCl}$ ).

\section{RESULTS AND DISCUSSION}

Figure 1 illustrates the synthesis of holey Fe-doped $\mathrm{Ni}(\mathrm{OH})_{2}$ nanosheets by a cation exchange reaction. Firstly, $\mathrm{Fe}^{3+}$ ions adsorb on the surface of $\mathrm{Ni}(\mathrm{OH})_{2}$ nanosheets, and they prefer to accumulating on the edge and defect sites. ${ }^{38-39}$ Then, $\mathrm{Fe}^{3+}$ and $\mathrm{Ni}^{2+}$ are involved in the cation exchange process, which means that partial lattice sites of $\mathrm{Ni}^{2+}$ are substituted with $\mathrm{Fe}^{3+}$. It is well known that $\mathrm{Ni}^{2+}$ could be replaced by $\mathrm{Fe}^{3+}$ in the $\mathrm{Ni}(\mathrm{OH})_{2}$ lattice, generating a stable LDH structure. ${ }^{40-42}$ It should be noted that, in addition to cation exchange, chemical etching might occur simultaneously accompanied with the generation of $\mathrm{Fe}(\mathrm{OH})_{3}$ (or $\mathrm{FeOOH}$ ). As a consequence, considerable amount of nanopores, grain boundaries and defects including $\mathrm{Ni}$ and $\mathrm{O}$ vacancies would be formed within basal planes accordingly after $\mathrm{Ni}^{2+}$ is dissolved. ${ }^{43-45}$ Hence, defect-enriched, holey, Fe-doped $\mathrm{Ni}(\mathrm{OH})_{2}$ nanosheets can be synthesized via this facile cationexchange process, and this unique structure would ensure the maximal exposure of active sites on the basal planes of doped $\mathrm{Ni}(\mathrm{OH})_{2}$ nanosheets. 


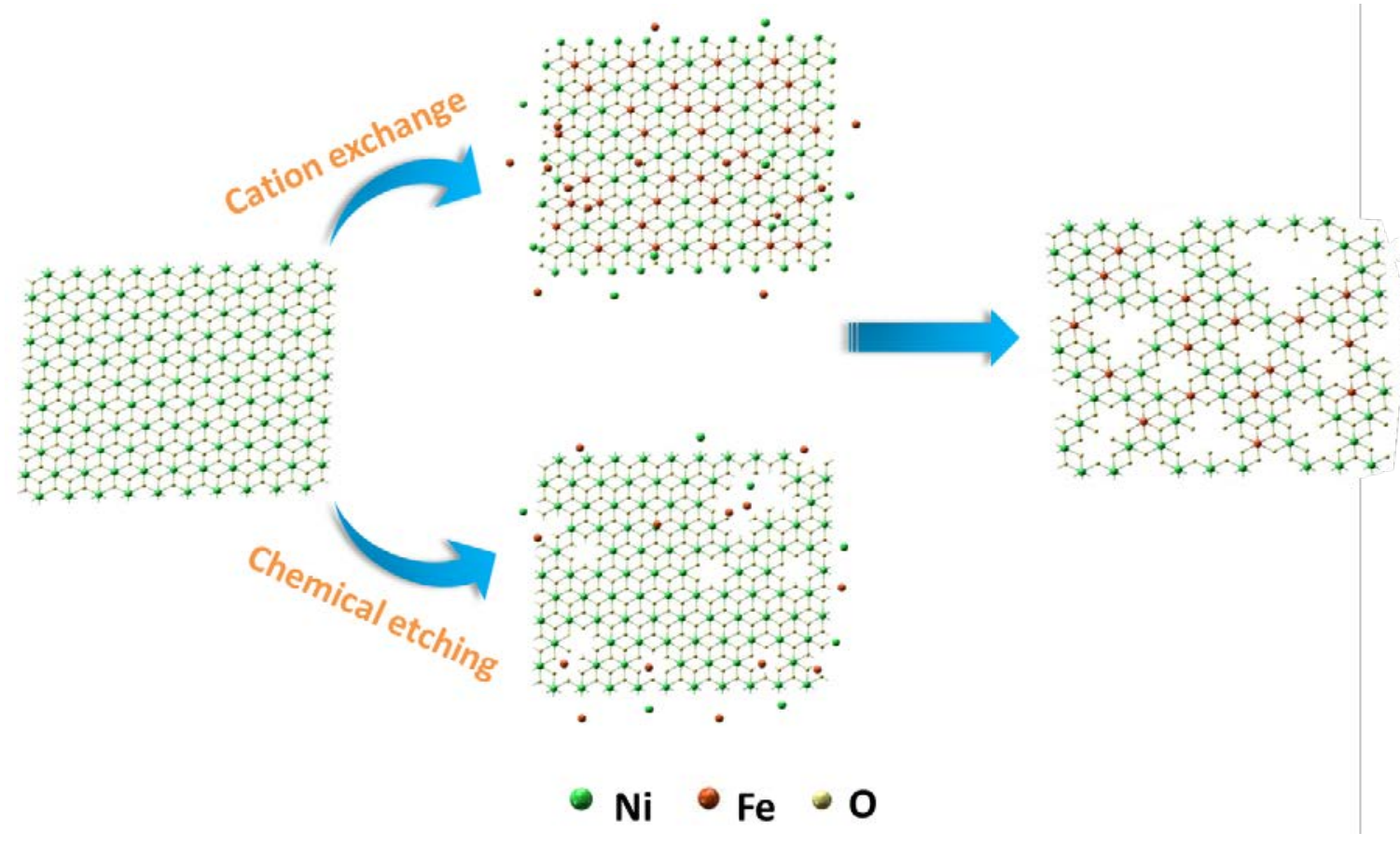

Figure 1. Schematic illustration of preparation of Fe-doped $\mathrm{Ni}(\mathrm{OH})_{2}$ nanosheets. Hydrogen atoms are omitted.

A series of Fe-doped $\mathrm{Ni}(\mathrm{OH})_{2}$ nanosheets $\left(\mathrm{Ni}_{1-\mathrm{x}} \mathrm{Fe}_{\mathrm{x}}(\mathrm{OH})_{2}\right)$ were synthesized by the cationexchange process, and Fe content was controlled by tuning the weight of $\mathrm{FeCl}_{3}$. The nominal composition of Fe-doped $\mathrm{Ni}(\mathrm{OH})_{2}$ nanosheets was determined to be $\mathrm{Ni}_{0.97} \mathrm{Fe}_{0.03}(\mathrm{OH})_{2}$, $\mathrm{Ni}_{0.83} \mathrm{Fe}_{0.17}(\mathrm{OH})_{2}$, and $\mathrm{Ni}_{0.77} \mathrm{Fe}_{0.23}(\mathrm{OH})_{2}$ for the reaction using 5, 12.5, and $20 \mathrm{mg} \mathrm{FeCl}_{3}$, respectively. Figure 2a displays the XRD patterns of $\mathrm{Ni}_{1-\mathrm{x}} \mathrm{Fe}_{\mathrm{x}}(\mathrm{OH})_{2}$ and pristine $\mathrm{Ni}(\mathrm{OH})_{2}$. As can be seen, $\mathrm{Ni}_{1-\mathrm{x}} \mathrm{Fe}_{\mathrm{x}}(\mathrm{OH})_{2}$ possess the same hexagonal phase structure with pristine $\mathrm{Ni}(\mathrm{OH})_{2}$ (JCPDS No. 38-0715), and the diffraction peaks located at around $11.5^{\circ}, 33.7^{\circ}$ and $59.9^{\circ}$ correspond to (003), (101) and (110) planes, respectively, suggesting that the crystal structure is well maintained after cation exchange. It is noteworthy that the (003) diffraction peak of $\mathrm{Ni}_{1}$ ${ }_{x} \mathrm{Fe}_{\mathrm{x}}(\mathrm{OH})_{2}$ shifts to higher angles as compared with $\mathrm{Ni}(\mathrm{OH})_{2}$, and this can be ascribed to the lattice shrinkage induced by the substitution of $\mathrm{Ni}^{2+}(69 \mathrm{pm})$ with smaller $\mathrm{Fe}^{3+}$ (55 pm). In 
addition, $\mathrm{NiFe} \mathrm{LDH}$ also shows similar $\mathrm{XRD}$ pattern to that of $\mathrm{Ni}_{1-\mathrm{x}} \mathrm{Fe}_{\mathrm{x}}(\mathrm{OH})_{2}$ (Figure $\mathrm{S} 1$, Supporting Information). Inset of Figure $2 \mathrm{a}$ shows photograph of $\mathrm{Ni}(\mathrm{OH})_{2}$ and $\mathrm{Ni}_{1-\mathrm{x}} \mathrm{Fe}_{\mathrm{x}}(\mathrm{OH})_{2}$ in ethanol solution. Obviously, the colour of products becomes more yellow with increasing of iron amount. TEM measurements were performed to investigate the microstructure of $\mathrm{Ni}_{1-\mathrm{x}} \mathrm{Fe}_{\mathrm{x}}(\mathrm{OH})_{2}$. Figure 2b presents a typical TEM image of $\mathrm{Ni}_{0.83} \mathrm{Fe}_{0.17}(\mathrm{OH})_{2}$, and clearly it shows thin nanosheet morphology, indicating that the nanosheet morphology of $\mathrm{Ni}(\mathrm{OH})_{2}$ (Figure S2a, Supporting Information) is inherited very well after cation exchange. Unlike pristine $\mathrm{Ni}(\mathrm{OH})_{2}$ and $\mathrm{NiFe}$ LDH nanosheets (Figure 2c and d) that have very smooth and flexible surface and good growth orientation, $\mathrm{Ni}_{0.83} \mathrm{Fe}_{0.17}(\mathrm{OH})_{2}$ (Figure 2e, Figure S3a-b, Supporting Information) nanosheets have a coarser surface and distinct grain boundaries appears. It can be observed from the atomic force microscope (AFM) images (Figure S4, Supporting Information) that the surface of $\mathrm{Ni}_{0.83} \mathrm{Fe}_{0.17}(\mathrm{OH})_{2}$ nanosheets is coarser than that of $\mathrm{NiFe} \mathrm{LDH}$. For $\mathrm{Ni}_{0.83} \mathrm{Fe}_{0.17}(\mathrm{OH})_{2}$, the thickness of the nanosheet varies from $0.8 \mathrm{~nm}$ to $1.3 \mathrm{~nm}$ with thickness fluctuation of $0.5 \mathrm{~nm}$ (Figure S4c, Supporting Information), which is much higher than that of NiFe LDH (0.2 nm). The higher the thickness fluctuation, the coarser the nanosheet is. It has to be mentioned that the increased surface roughness would increase the hydrophilicity of the active materials, ${ }^{46-47}$ which is beneficial to mass diffusion kinetics in aqueous media. As shown in the high-resolution TEM (HRTEM) (Figure 2f), the lattice fringes with a spacing of $0.15 \mathrm{~nm}$ can be assigned to (110) planes of $\mathrm{Ni}_{0.83} \mathrm{Fe}_{0.17}(\mathrm{OH})_{2}$. Notably, the lattice spacing of $0.22 \mathrm{~nm}$ corresponds to the (020) planes of FeOOH (JCPDS No. 26-0792) (Figure S3c and d, Supporting Information), and this confirms the occurrence of chemical etching besides cation exchange. Moreover, the formation of nanopores (ca. $1 \mathrm{~nm}$ ) in $\mathrm{Ni}_{0.83} \mathrm{Fe}_{0.17}(\mathrm{OH})_{2}$ nanosheets can be clearly observed from the HAADF-STEM image (Figure 2g). Such holey nanosheet morphology is more beneficial to the 
formation of active phase with high valence than the nanosheets with close-packed basal planes. ${ }^{8}$, 22, 24 Furthermore, the holey structure also helps to accelerate electrolyte penetration and the release of gas bubbles. ${ }^{48}$ Both $\mathrm{Ni}_{0.97} \mathrm{Fe}_{0.03}(\mathrm{OH})_{2}$ and $\mathrm{Ni}_{0.77} \mathrm{Fe}_{0.23}(\mathrm{OH})_{2}$, show similar morphology to $\mathrm{Ni}_{0.83} \mathrm{Fe}_{0.17}(\mathrm{OH})_{2}$, as can be seen from Figure S5 (Supporting Information). It has to be mentioned that $\mathrm{Ni}_{0.97} \mathrm{Fe}_{0.03}(\mathrm{OH})_{2}$ merely endows abundant grain boundaries without obvious nanopores, while nanopores can be clearly observed in $\mathrm{Ni}_{0.77} \mathrm{Fe}_{0.23}(\mathrm{OH})_{2}$, indicating enhanced chemical etching with increasing $\mathrm{Fe}^{3+}$. And the yield of $\mathrm{Ni}_{1-\mathrm{x}} \mathrm{Fe}_{\mathrm{x}}(\mathrm{OH})_{2}$ decreases dramatically with increasing $\mathrm{Fe}^{3+}$ during reaction, further confirming more severe etching. In addition, the STEM elemental mappings, as shown in Figure 2h, reveal uniform distribution of Ni, Fe and O in $\mathrm{Ni}_{0.83} \mathrm{Fe}_{0.17}(\mathrm{OH})_{2}$ nanosheets, revealing that $\mathrm{Fe}^{3+}$ doping is achieved uniformly in the nanosheets by this cation-exchange process. As can be seen form the Raman spectroscopy (Figure S6, Supporting Information), $\mathrm{Ni}_{0.83} \mathrm{Fe}_{0.17}(\mathrm{OH})_{2}$ exhibits a similar broad peak to $\mathrm{NiFe}$ $\mathrm{LDH}$ at around $531 \mathrm{~cm}^{-1}$, which is corresponding to Fe-O bond, ${ }^{30}$ while this peak is absent for pristine $\mathrm{Ni}(\mathrm{OH})_{2}$. The Raman results further validate that $\mathrm{Fe}^{3+}$ is successfully doped into $\mathrm{Ni}(\mathrm{OH})_{2}$ via $\mathrm{Fe}^{3+} / \mathrm{Ni}^{2+}$ exchange reaction. 

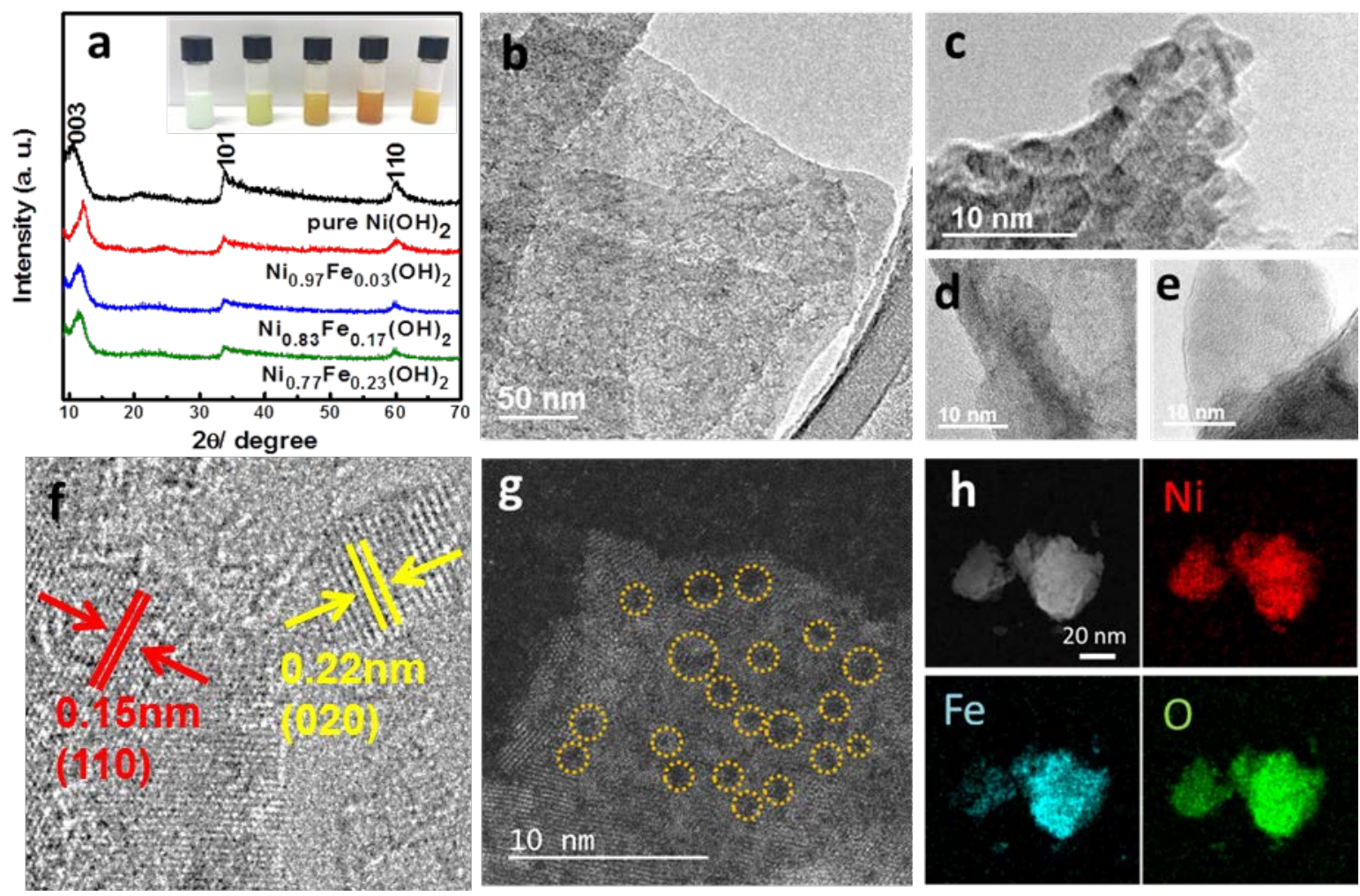

Figure 2. (a) XRD pattern of $\mathrm{Ni}(\mathrm{OH})_{2}$ and $\mathrm{Ni}_{1-\mathrm{x}} \mathrm{Fe}_{\mathrm{x}}(\mathrm{OH})_{2}$; TEM images of $\mathrm{Ni}_{0.83} \mathrm{Fe}_{0.17}(\mathrm{OH})_{2}$ (b, c), $\mathrm{Ni}(\mathrm{OH})_{2}$ (d), and $\mathrm{NiFe} \mathrm{LDH}$ (e); (f) HRTEM of $\mathrm{Ni}_{0.83} \mathrm{Fe}_{0.17}(\mathrm{OH})_{2}$; (g) atomic resolution HAADF-STEM image of $\mathrm{Ni}_{0.83} \mathrm{Fe}_{0.17}(\mathrm{OH})_{2}$ nanosheets; (h) HAADF-STEM image and corresponding elemental mappings of $\mathrm{Ni}_{0.83} \mathrm{Fe}_{0.17}(\mathrm{OH})_{2}$. Inset of Figure 2a is digital photos of $\mathrm{Ni}(\mathrm{OH})_{2}, \mathrm{Ni}_{0.97} \mathrm{Fe}_{0.03}(\mathrm{OH})_{2}, \mathrm{Ni}_{0.83} \mathrm{Fe}_{0.17}(\mathrm{OH})_{2}, \mathrm{Ni}_{0.77} \mathrm{Fe}_{0.23}(\mathrm{OH})_{2}$, and $\mathrm{NiFe} \mathrm{LDH}$ (from left to right) dispersed in ethanol.

Figure 3a shows the survey scan XPS spectrum of $\mathrm{Ni}_{0.83} \mathrm{Fe}_{0.17}(\mathrm{OH})_{2}$, and all the peaks are labelled and reveal the existence of $\mathrm{Ni}, \mathrm{Fe}$, and $\mathrm{O}$. As can be seen from Figure 3b, two peaks located around $856.1 \mathrm{eV}$ and $873.7 \mathrm{eV}$ correspond to $\mathrm{Ni} 2 \mathrm{p}_{3 / 2}$ and $\mathrm{Ni} 2 \mathrm{p}_{1 / 2}$, respectively, and the spin-energy separation of $17.6 \mathrm{eV}$ is the characteristic of $\mathrm{Ni}^{2+}$ in $\mathrm{Ni}(\mathrm{OH})_{2} \cdot{ }^{49}$ In Figure 3c, the peaks with binding energy of $712.5 \mathrm{eV}$ and 725.5 correspond to $\mathrm{Fe} 2 \mathrm{p}_{3 / 2}$ and Fe 2p $1 / 2$, 
respectively. After fitting, the peaks at 713.4 and $726.6 \mathrm{eV}$ correspond to Fe 22 $\mathrm{p}_{3 / 2}$ and Fe 2 $\mathrm{p}_{1 / 2}$ of Fe-OH in $\mathrm{Ni}_{0.83} \mathrm{Fe}_{0.17}(\mathrm{OH})_{2},{ }^{50}$ and the peaks at 711.0 and $724.6 \mathrm{eV}$ can be assigned to $\mathrm{Fe} 2 \mathrm{p}_{3 / 2}$ and $\mathrm{Fe} 2 \mathrm{p}_{1 / 2}$ of FeOOH. ${ }^{51}$ With regard to the high-resolution spectrum for $\mathrm{O}$ 1s (Figure 3d), the peaks at 532.2, 531.2, and $529.5 \mathrm{eV}$ can be attributed to water molecules adsorbed on nanosheets surface, hydroxyl groups in $\mathrm{Ni}_{0.83} \mathrm{Fe}_{0.17}(\mathrm{OH})_{2}$, and lattice oxygen in $\mathrm{FeOOH} .{ }^{52-53}$ Notably, both the peaks of $\mathrm{Fe} 2 \mathrm{p}_{3 / 2}$ and $\mathrm{Fe} 2 \mathrm{p}_{1 / 2}$ shift to lower binding energy with increasing $\mathrm{Fe}^{3+}$ during reaction (Figure S7, Supporting Information), which can be ascribed to the increment of FeOOH. This phenomenon is also confirmed by the O1s spectrum (Figure S8, Supporting Information), and the proportion of lattice oxygen increases gradually with the increase of iron doping amount. Specifically, the percentage of $\mathrm{FeOOH}$ in $\mathrm{Ni}_{0.97} \mathrm{Fe}_{0.03}(\mathrm{OH})_{2}, \quad \mathrm{Ni}_{0.83} \mathrm{Fe}_{0.17}(\mathrm{OH})_{2}$ and $\mathrm{Ni}_{0.77} \mathrm{Fe}_{0.23}(\mathrm{OH})_{2}$ is determined to be around $1.5 \%, 3.2 \%$ and $5.3 \%$, respectively.
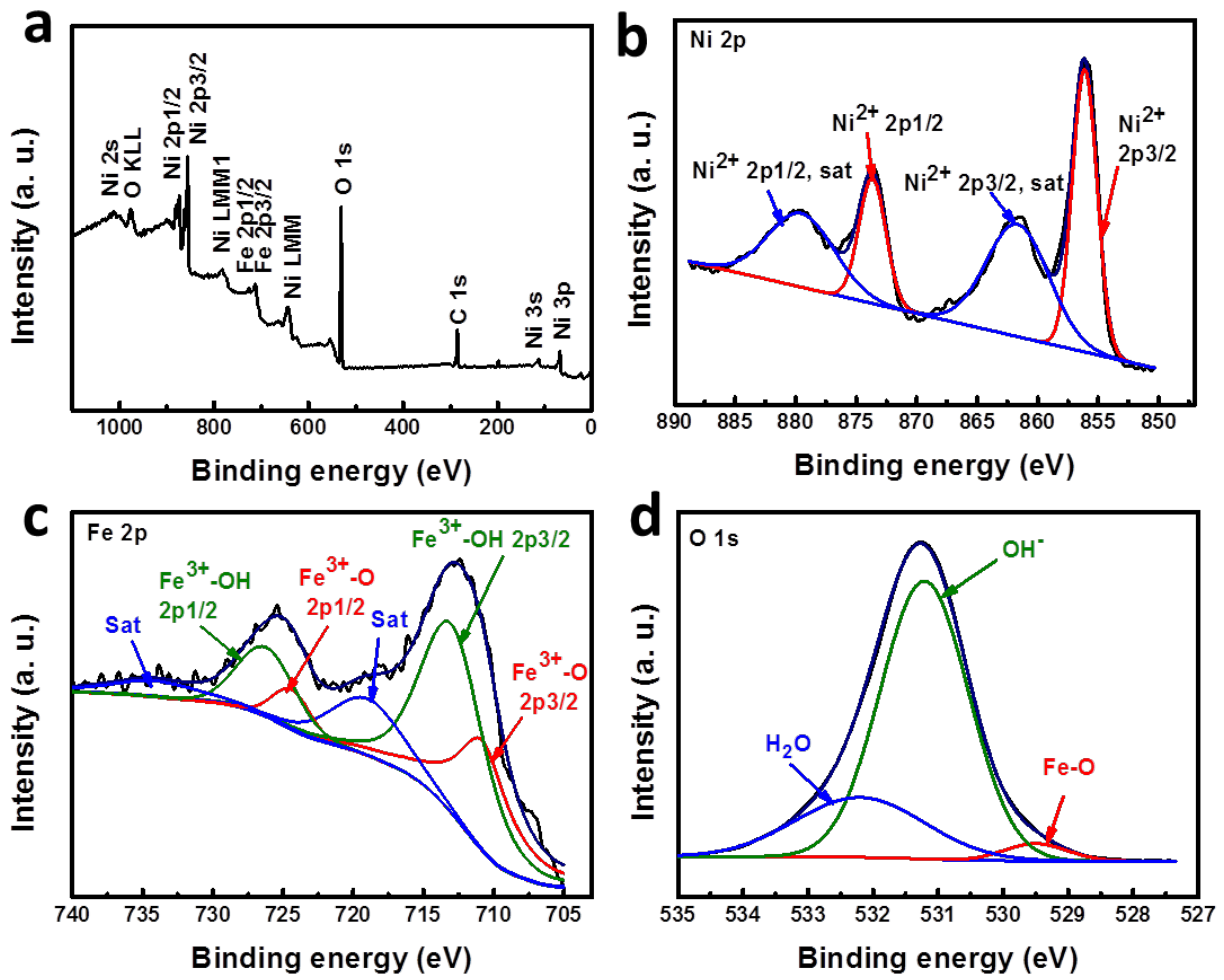

Figure 3. XPS spectra of $\mathrm{Ni}_{0.83} \mathrm{Fe}_{0.17}(\mathrm{OH})_{2}$ : (a) survey spectrum, (b) Ni 2p, (c) Fe 2p and (d) O $1 \mathrm{s.}$ 
The catalytic activity of $\mathrm{Ni}_{1-\mathrm{x}} \mathrm{Fe}_{\mathrm{x}}(\mathrm{OH})_{2}$ along with pristine $\mathrm{Ni}(\mathrm{OH})_{2}$ and $\mathrm{NiFe} \mathrm{LDH}$ was measured using a rotating disk electrode in $\mathrm{O}_{2}$-saturated $1 \mathrm{M} \mathrm{KOH}$ solution. Figure 4a shows representative iR-corrected LSV polarization curves of the samples. In the polarization curve of $\mathrm{Ni}(\mathrm{OH})_{2}$, the peak at around $1.42 \mathrm{~V}$ versus $\mathrm{RHE}$ is associated with the redox reaction of $\mathrm{Ni}^{2+} / \mathrm{Ni}^{3+} .^{54}$ Notably, this redox reaction appears at a higher potential for $\mathrm{Ni}_{0.83} \mathrm{Fe}_{0.17}(\mathrm{OH})_{2}$ and $\mathrm{NiFe} \mathrm{LDH}$, possibly due to the electronic structure change of the material after Fe incorporation, and this potential shift is also a good indicator to determine whether Fe is doped into $\mathrm{Ni}(\mathrm{OH})_{2}$ or $\mathrm{Co}(\mathrm{OH})_{2}$ catalysts. ${ }^{55-56}$ Clearly, the catalytic ability of $\mathrm{Ni}_{1-\mathrm{x}} \mathrm{Fe}_{\mathrm{x}}(\mathrm{OH})_{2}$ varies significantly with $\mathrm{Fe}$ doping content. In particular, $\mathrm{Ni}_{0.83} \mathrm{Fe}_{0.17}(\mathrm{OH})_{2}$ shows the best OER performance, which is substantially enhanced as compared with other samples. To reach a current density of $10 \mathrm{~mA} \mathrm{~cm}^{-}$ ${ }^{2}$, a low overpotential of only $245 \mathrm{mV}$ is required for $\mathrm{Ni}_{0.83} \mathrm{Fe}_{0.17}(\mathrm{OH})_{2}$, which is 115 and $65 \mathrm{mV}$ lower than that of pristine $\mathrm{Ni}(\mathrm{OH})_{2}$ and $\mathrm{NiFe} \mathrm{LDH}$, respectively (Figure 4b). It has to be noted that the catalytic performance of $\mathrm{Ni}_{0.83} \mathrm{Fe}_{0.17}(\mathrm{OH})_{2}$ is among the best of the reported $\mathrm{Ni}(\mathrm{OH})_{2}$ and NiFe LDH catalysts tested under similar conditions, and is even comparable to that of the samples with conductive substrates (e.g., nickel foam) or conductive additives (e.g., carbon nanotubes) (Table S1, Supporting Information). In addition, $\mathrm{Ni}_{0.97} \mathrm{Fe}_{0.03}(\mathrm{OH})_{2}$ and $\mathrm{Ni}_{0.77} \mathrm{Fe}_{0.23}(\mathrm{OH})_{2}$ also exhibit better catalytic performance than pristine $\mathrm{Ni}(\mathrm{OH})_{2}$. The electrocatalytic ability of $\mathrm{Ni}_{1-\mathrm{x}} \mathrm{Fe}_{\mathrm{x}}(\mathrm{OH})_{2}$ is well consistent with previous reports that the OER performance of $\mathrm{Ni}(\mathrm{OH})_{2}$-based catalysts can be greatly improved after Fe incorporation. ${ }^{17,36,57}$ The exact reason for Fe doping-induced performance improvement is still under debate. ${ }^{36,58}$ It was proposed that $\mathrm{Fe}$ doping into $\mathrm{Ni}(\mathrm{OH})_{2}$ may result in conductivity improvement and accelerated charge transfer from $\mathrm{Fe}$ sites to $\mathrm{Ni}$ active centers, thereby inducing enhanced 
catalytic performance. ${ }^{36}$ However, $\mathrm{Li}$ et al. hypothesized that the Lewis acidity of $\mathrm{Fe}^{3+}$ would increase Ni-O hybridization, thus resulting in improved catalytic activity. ${ }^{58}$ Based on the aforementioned discussion, $\mathrm{Ni}_{0.77} \mathrm{Fe}_{0.23}(\mathrm{OH})_{2}$ contains considerable amount of $\mathrm{FeOOH}$, which is nearly electrochemically inert for OER (Figure S9, Supporting Information), and the inactive FeOOH nanograins located on nanosheets surface also hinder exposure of the active sites. Consequently, the catalytic activity of $\mathrm{Ni}_{0.77} \mathrm{Fe}_{0.23}(\mathrm{OH})_{2}$ deteriorates severely as compare with $\mathrm{Ni}_{0.83} \mathrm{Fe}_{0.17}(\mathrm{OH})_{2}$. The improved catalytic kinetics of $\mathrm{Ni}_{0.83} \mathrm{Fe}_{0.17}(\mathrm{OH})_{2}$ is also evidenced by its reduced Tafel slope, as shown in Figure 4c. The Tafel slope of $\mathrm{Ni}_{0.83} \mathrm{Fe}_{0.17}(\mathrm{OH})_{2}$ is $61 \mathrm{mV} \mathrm{dec}{ }^{-1}$, which is lower than both of $\mathrm{Ni}(\mathrm{OH})_{2}\left(72 \mathrm{mV} \mathrm{dec}^{-1}\right)$ and NiFe LDH $\left(78 \mathrm{mV} \mathrm{dec}^{-1}\right)$. Furthermore, as shown in Figure 4d, the current density of $\mathrm{Ni}_{0.83} \mathrm{Fe}_{0.17}(\mathrm{OH})_{2}$ reaches as high as $41 \mathrm{~mA} \mathrm{~cm}{ }^{-2}$ at an overpotential of $300 \mathrm{mV}$, which is 20 and 5 times higher than those of $\mathrm{Ni}(\mathrm{OH})_{2}\left(2.0 \mathrm{~mA} \mathrm{~cm}^{-2}\right)$ and NiFe LDH $\left(7.5 \mathrm{~mA} \mathrm{~cm}{ }^{-2}\right)$, respectively. Figure 4e shows the performance durability of $\mathrm{Ni}_{0.83} \mathrm{Fe}_{0.17}(\mathrm{OH})_{2}$ evaluated at $10 \mathrm{~mA} \mathrm{~cm}{ }^{-2}$. One can see that the potential only increases by 20 $\mathrm{mV}$ during 10-h operation, suggesting very promising catalytic performance stability. Moreover, even after accelerated electrochemical aging (electrochemical cycling between 1.023 and 1.623 V vs. RHE, 200 cycles), $\mathrm{Ni}_{0.83} \mathrm{Fe}_{0.17}(\mathrm{OH})_{2}$ possess almost unchanged morphology, and the nanopores $(1-2 \mathrm{~nm})$ on the nanosheets can still be clearly observed (Figure S10, Supporting Information), revealing good morphology stability of the $\mathrm{Ni}_{0.83} \mathrm{Fe}_{0.17}(\mathrm{OH})_{2}$ nanosheets over cycling. 

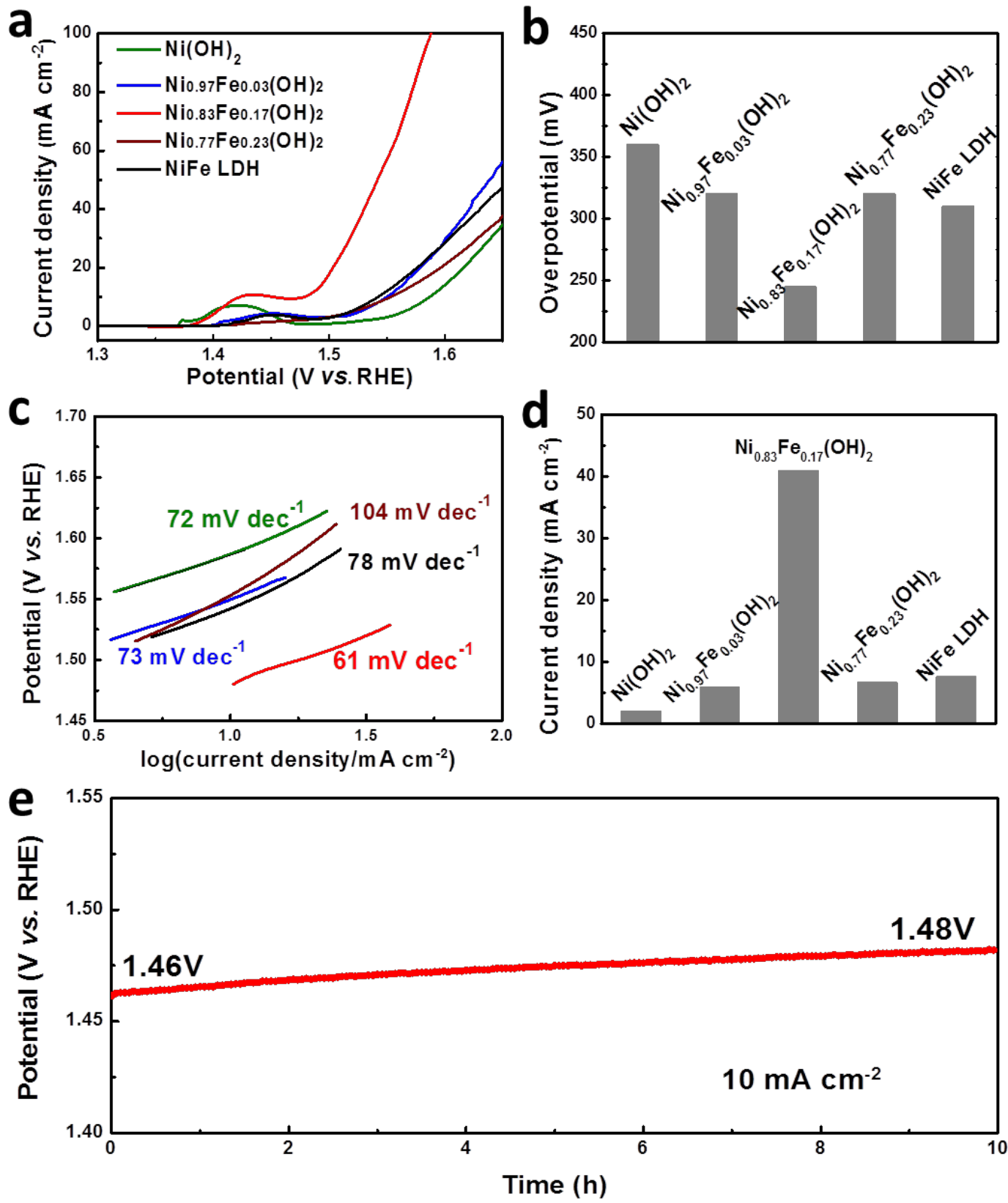

Figure 4. (a) iR-corrected LSV polarization curves measured at a scan rate of $5 \mathrm{mV} \mathrm{s}^{-1}$ in $1 \mathrm{M}$ KOH solution, (b) overpotential required at $10 \mathrm{~mA} \mathrm{~cm}^{-2}$, (c) tafel plots derived from LSV curves, (d) current densities at an overpotential of $300 \mathrm{mV}$, (e) chronopotentiometry curve of $\mathrm{Ni}_{0.83} \mathrm{Fe}_{0.17}(\mathrm{OH})_{2}$ at a constant current density of $10 \mathrm{~mA} \mathrm{~cm}{ }^{-2}$. 
It has to be noted that, besides pristine $\mathrm{Ni}(\mathrm{OH})_{2}$ nanosheets, the catalytic activity of $\mathrm{Ni}_{0.83} \mathrm{Fe}_{0.17}(\mathrm{OH})_{2}$ also significantly outperforms NiFe LDH with similar chemical composition $\left(\mathrm{Ni}_{0.85} \mathrm{Fe}_{0.15}(\mathrm{OH})_{2}\right)$ that is prepared via a one-step solvothermal process. The enhanced OER activity of $\mathrm{Ni}_{0.83} \mathrm{Fe}_{0.17}(\mathrm{OH})_{2}$ over $\mathrm{NiFe} \mathrm{LDH}$ can be attributed to the defect-enriched holey basal planes of $\mathrm{Ni}_{0.83} \mathrm{Fe}_{0.17}(\mathrm{OH})_{2}$ prepared via the cation-exchange process. Firstly, the holey nanosheet morphology along with abundant $\mathrm{Ni}$ and $\mathrm{O}$ vacancies, which are induced by chemical etching of $\mathrm{Fe}^{3+}$, help to expose more ion-accessible sites and hence more active sites. The double layer capacitance $\left(\mathrm{C}_{\mathrm{dl}}\right)$ determined based on the $\mathrm{CV}$ curves is used to roughly represent the corresponding ECSA of the samples. As can be seen from Figure S11 (Supporting Information), the current density of $\mathrm{Ni}_{0.83} \mathrm{Fe}_{0.17}(\mathrm{OH})_{2}$ is much higher than that of NiFe LDH. The linear slope of NiFe LDH is $2.0 \mathrm{mF} \mathrm{cm}{ }^{-2}$, while $\mathrm{Ni}_{0.83} \mathrm{Fe}_{0.17}(\mathrm{OH})_{2}$ has a higher linear slope of $7.6 \mathrm{mF} \mathrm{cm}{ }^{-2}$ (Figure 5a), which means $\mathrm{Ni}_{0.83} \mathrm{Fe}_{0.17}(\mathrm{OH})_{2}$ possesses higher ECSA than NiFe LDH. Secondly, $\mathrm{Ni}_{0.83} \mathrm{Fe}_{0.17}(\mathrm{OH})_{2}$ exhibits better wettability than $\mathrm{NiFe} \mathrm{LDH}$ and pristine $\mathrm{Ni}(\mathrm{OH})_{2}$. As shown in Figure 5c-e, the static contact angle is $25^{\circ}$ and $32^{\circ}$ for pristine $\mathrm{Ni}(\mathrm{OH})_{2}$ and $\mathrm{NiFe} \mathrm{LDH}$. In contrast, the contact angle of $\mathrm{Ni}_{0.83} \mathrm{Fe}_{0.17}(\mathrm{OH})_{2}$ decreases to $13^{\circ}$, revealing a much more hydrophilic surface. The improved catalyst surface wettability would ensure fast electrolyte penetration and accelerate migration of hydroxyl groups and oxygen release as well. ${ }^{48,59-60}$ Figure 5b presents the electrochemical impedance spectra (EIS) of $\mathrm{Ni}_{0.83} \mathrm{Fe}_{0.17}(\mathrm{OH})_{2}$ and $\mathrm{NiFe}$ LDH. Both EIS curves consist of two apparent semicircles. Basically, the high-frequency semicircle is mainly associated with charge transfer resistance and the low-frequency semicircle is related to the mass-diffusion process. ${ }^{61}$ Clearly, both charge transfer and mass-diffusion resistances of $\mathrm{Ni}_{0.83} \mathrm{Fe}_{0.17}(\mathrm{OH})_{2}$ are significantly reduced compared with $\mathrm{NiFe} \mathrm{LDH}$, and this can be mainly ascribed to the holey nanosheets composed of nanograins and improved wettability of 
$\mathrm{Ni}_{0.83} \mathrm{Fe}_{0.17}(\mathrm{OH})_{2}$. The high ECSA and decreased resistances eventually result in substantially accelerated reaction kinetics for $\mathrm{Ni}_{0.83} \mathrm{Fe}_{0.17}(\mathrm{OH})_{2}$.
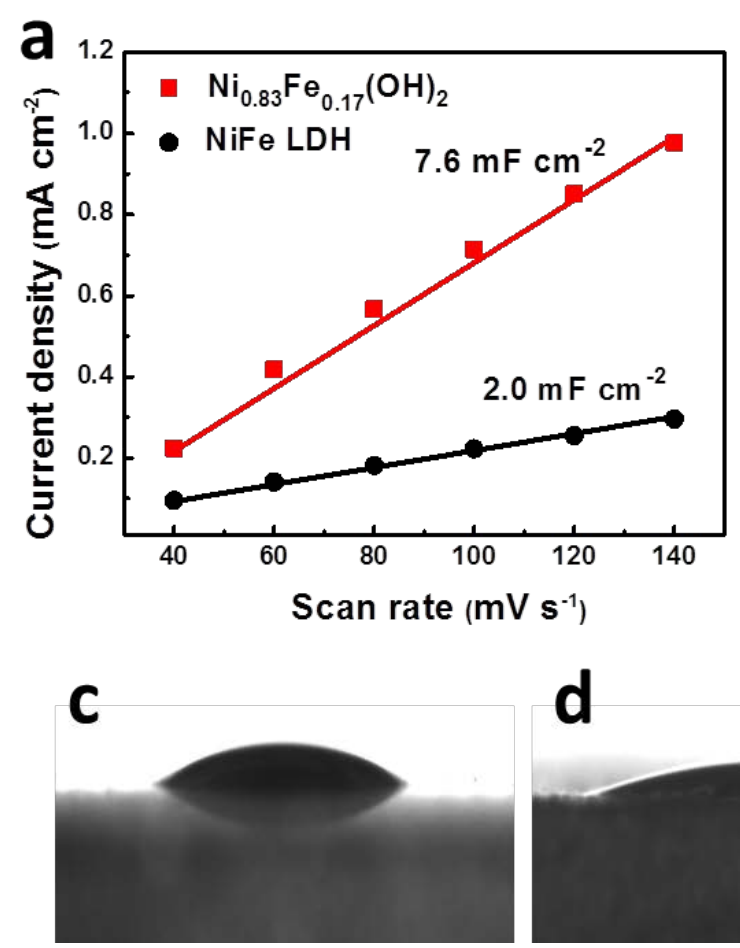

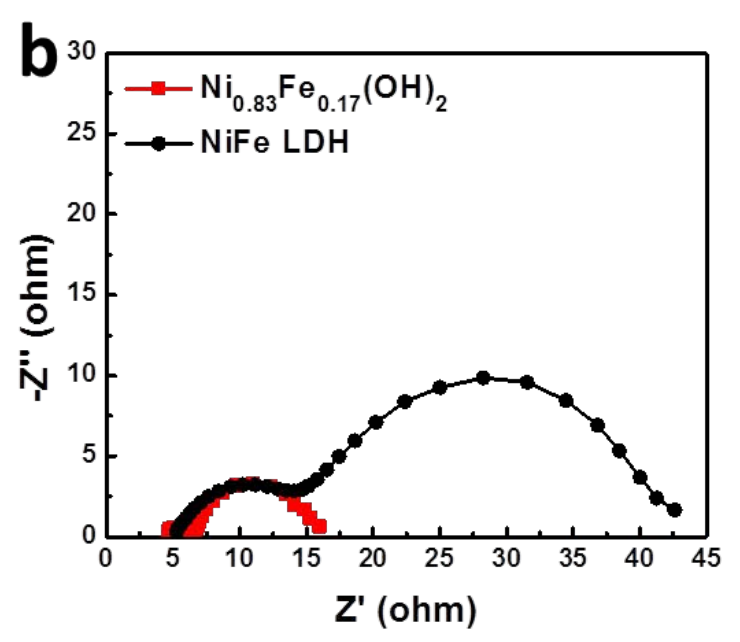

e
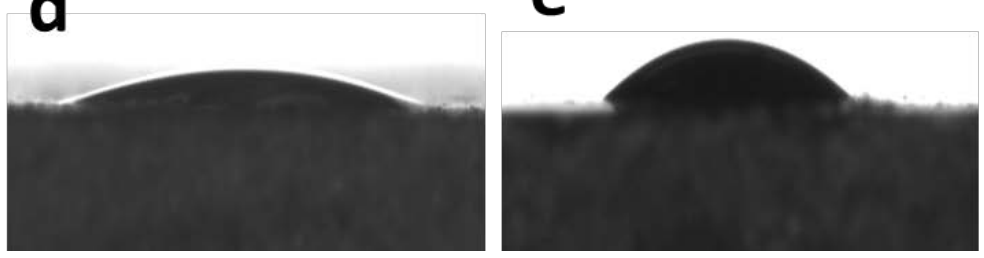

Figure 5. (a) Current density differences at $0.375 \mathrm{~V}$ (vs. Ag/AgCl) plotted against the scan rate measured in a non-Faradaic range. (b) Electrochemical impedance spectra measured at $0.5 \mathrm{~V}$ (vs. $\mathrm{Ag} / \mathrm{AgCl}$ ). Contact angle measurements of (c) pure $\mathrm{Ni}(\mathrm{OH})_{2}$, (d) $\mathrm{Ni}_{0.83} \mathrm{Fe}_{0.17}(\mathrm{OH})_{2}$ and (e) $\mathrm{NiFe}$ LDH.

This facile cation-exchange process is also successfully extended to synthesize Fe-doped $\mathrm{Co}(\mathrm{OH})_{2}$ nanosheets (Figure S12, Supporting Information). As shown in Figure S13 (Supporting Information), Fe-doped $\mathrm{Co}(\mathrm{OH})_{2}$ nanosheets contain significant grain boundaries and have rougher surface after $\mathrm{Fe}^{3+} / \mathrm{Co}^{2+}$ cation exchange reaction. Moreover, improved hydrophilicity is also achieved after Fe incorporation (Figure S14, Supporting Information). Similar to Fe-doped $\mathrm{Ni}(\mathrm{OH})_{2}$, Fe-doped $\mathrm{Co}(\mathrm{OH})_{2}$ delivers better catalytic performance than that of pristine $\mathrm{Co}(\mathrm{OH})_{2}$ nanosheets. As can be seen from Figure S15 (Supporting Information), Fe-doped $\mathrm{Co}(\mathrm{OH})_{2}$ shows 
lower overpotential and Tafel slope ( $320 \mathrm{mV}$ at $10 \mathrm{~mA} \mathrm{~cm}^{-2}, 53 \mathrm{mV} \mathrm{dec}{ }^{-1}$ ) than those of pristine $\mathrm{Co}(\mathrm{OH})_{2}\left(370 \mathrm{mV}\right.$ at $\left.10 \mathrm{~mA} \mathrm{~cm}{ }^{-2}, 69 \mathrm{mV} \mathrm{dec}^{-1}\right)$. The enhanced performance of Fe-doped $\mathrm{Co}(\mathrm{OH})_{2}$ can also be ascribed to the altered electronic property of $\mathrm{Co}(\mathrm{OH})_{2}$ after Fe doping, increased grain boundaries and consequently more active sites. The results demonstrate that this cation exchange process is universal for preparing highly active $\mathrm{Ni}(\mathrm{OH})_{2}$ - and $\mathrm{Co}(\mathrm{OH})_{2}$-based OER catalysts.

\section{CONCLUSION}

In summary, a general cation exchange process was developed to synthesize efficient $\mathrm{Ni}(\mathrm{OH})_{2-}$ and $\mathrm{Co}(\mathrm{OH})_{2}$-based catalysts for oxygen evolution catalysis. As a proof-of-concept application,

holey Fe-doped $\mathrm{Ni}(\mathrm{OH})_{2}$ nanosheets with abundant defects were prepared via $\mathrm{Fe}^{3+} / \mathrm{Ni}^{2+}$ cation exchange, and showed high electrochemical active surface area and improved surface wettability. Consequently, the active site-enriched Fe-doped $\mathrm{Ni}(\mathrm{OH})_{2}$ nanosheets delivered substantially enhanced catalytic performance over pristine $\mathrm{Ni}(\mathrm{OH})_{2}$ and $\mathrm{NiFe} \mathrm{LDH}$. Moreover, highly active Fe-doped $\mathrm{Co}(\mathrm{OH})_{2}$ nanosheets were also successfully prepared via the similar process. We believe that this novel strategy would shed light on developing high-performance heteroatom-doped catalysts with abundant active sites.

\section{ASSOCIATED CONTENT}

\section{Supporting Information}

The Supporting Information is available free of charge.

XRD, TEM, XPS, and additional characterization information as detailed in the text. 


\section{AUTHOR INFORMATION}

\section{Corresponding Author}

linyue@ustc.edu.cn (Y. Lin)

xun@uow.edu.au (X.Xu)

wenping@uow.edu.au (W.Sun)

Notes

The authors declare no competing financial interest.

\section{ACKNOWLEDGEMENTS}

This work was financially supported by the Australian Research Council (ARC) DECRA Grant (DE160100596), ARC Discovery Project (DP160102627), an AIIM-MANA Joint Seed Grant (2017), and AIIM FOR GOLD Grant (2017, 2018). Y. Lin thanks financial support by the Young Scientists Fund of the National Natural Science Foundation of China (11404314) and Anhui Provincial Natural Science Foundation (1708085MA06). The authors also acknowledge use of facilities within the UOW Electron Microscopy Centre.

\section{REFERENCES}

1. Cheng, F.; Chen, J. Metal-Air Batteries: From Oxygen Reduction Electrochemistry to Cathode Catalysts. Chem. Soc. Rev. 2012, 41, 2172-2192.

2. $\quad$ Cook, T. R.; Dogutan, D. K.; Reece, S. Y.; Surendranath, Y.; Teets, T. S.; Nocera, D. G. Solar Energy Supply and Storage for the Legacy and Nonlegacy Worlds. Chem.Rev. 2010, 110, 6474-6502.

3. Gray, H. B. Powering the Planet with Solar Fuel. Nat. chem. 2009, 1, 7-7.

4. $\quad$ Lee, S. W.; Carlton, C.; Risch, M.; Surendranath, Y.; Chen, S.; Furutsuki, S.; Yamada, A.; Nocera, D. G.; Shao-Horn, Y. The Nature of Lithium Battery Materials under Oxygen Evolution Reaction Conditions. J. Am. Chem. Soc. 2012, 134, 16959-16962.

5. Liu, X.; Park, M.; Kim, M. G.; Gupta, S.; Wu, G.; Cho, J. Integrating NiCo Alloys with Their Oxides as Efficient Bifunctional Cathode Catalysts for Rechargeable Zinc-Air Batteries. Angew. Chem., Int. Ed. 2015, 54, 9654-9658.

6. Suntivich, J.; May, K. J.; Gasteiger, H. A.; Goodenough, J. B.; Shao-Horn, Y. A Perovskite Oxide Optimized for Oxygen Evolution Catalysis from Molecular Orbital Principles. Science 2011, 334, 1383-1385. 
7. Wang, J.; Zhong, H. X.; Qin, Y.L.; Zhang, X. B. An Efficient Three-Dimensional Oxygen Evolution Electrode. Angew. Chem. 2013, 125, 5356-5361.

8. Burke, M. S.; Kast, M. G.; Trotochaud, L.; Smith, A. M.; Boettcher, S. W. Cobalt-Iron (Oxy) Hydroxide Oxygen Evolution Electrocatalysts: The Role of Structure and Composition on Activity, Stability, and Mechanism. J. Am. Chem. Soc. 2015, 137, 3638-3648.

9. $\quad$ Chen, Y.; Zhou, Q.; Zhao, G.; Yu, Z.; Wang, X.; Dou, S. X.; Sun, W. Electrochemically Inert g- $\mathrm{C}_{3} \mathrm{~N}_{4}$ Promotes Water Oxidation Catalysis. Adv. Funct. Mater. 2018, 28, 1705583.

10. Tang, C.; Wang, H. S.; Wang, H. F.; Zhang, Q.; Tian, G. L.; Nie, J. Q.; Wei, F. Spatially Confined Hybridization of Nanometer-Sized NiFe Hydroxides into Nitrogen-Doped Graphene Frameworks Leading to Superior Oxygen Evolution Reactivity. Adv. Mater. 2015, 27, 45164522.

11. Zhao, Z.; Wu, H.; He, H.; Xu, X.; Jin, Y. A High-Performance Binary Ni-Co HydroxideBased Water Oxidation Electrode with Three-Dimensional Coaxial Nanotube Array Structure. Adv. Funct. Mater. 2014, 24, 4698-4705.

12. Gong, M.; Li, Y.; Wang, H.; Liang, Y.; Wu, J. Z.; Zhou, J.; Wang, J.; Regier, T.; Wei, F.; Dai, H. An Advanced Ni-Fe Layered Double Hydroxide Electrocatalyst for Water Oxidation. $J$. Am. Chem. Soc 2013, 135, 8452-8455.

13. Han, N.; Zhao, F.; Li, Y. Ultrathin Nickel-Iron Layered Double Hydroxide Nanosheets Intercalated with Molybdate Anions for Electrocatalytic Water Oxidation. J. Mater. Chem. A 2015, 3, 16348-16353.

14. Song, F.; Hu, X. Exfoliation of Layered Double Hydroxides for Enhanced Oxygen Evolution Catalysis. Nat. commun. 2014, 5.

15. Yan, K.; Lafleur, T.; Chai, J.; Jarvis, C. Facile Synthesis of Thin NiFe-Layered Double Hydroxides Nanosheets Efficient for Oxygen Evolution. Electrochem. Commun. 2016, 62, 24-28. 16. Yu, L.; Zhou, H.; Sun, J.; Qin, F.; Yu, F.; Bao, J.; Yu, Y.; Chen, S.; Ren, Z. Cu Nanowires Shelled with NiFe Layered Double Hydroxide Nanosheets as Bifunctional Electrocatalysts for Overall Water Splitting. Energ. Environ. Sci. 2017, 10, 1820-1827.

17. Zhu, K.; Liu, H.; Li, M.; Li, X.; Wang, J.; Zhu, X.; Yang, W. Atomic-Scale Topochemical Preparation of Crystalline $\mathrm{Fe}^{3+}$-Doped $\beta$-Ni(OH $)_{2}$ for an Ultrahigh-Rate Oxygen Evolution Reaction. J. Mater, Chem, A 2017, 5, 7753-7758.

18. Long, X.; Li, J.; Xiao, S.; Yan, K.; Wang, Z.; Chen, H.; Yang, S. A Strongly Coupled Graphene and FeNi Double Hydroxide Hybrid as an Excellent Electrocatalyst for the Oxygen Evolution Reaction. Angew. Chem. 2014, 126, 7714-7718.

19. Ma, W.; Ma, R.; Wang, C.; Liang, J.; Liu, X.; Zhou, K.; Sasaki, T. A Superlattice of Alternately Stacked Ni-Fe Hydroxide Nanosheets and Graphene for Efficient Splitting of Water. ACS nano 2015, 9, 1977-1984.

20. Tang, D.; Liu, J.; Wu, X.; Liu, R.; Han, X.; Han, Y.; Huang, H.; Liu, Y.; Kang, Z. Carbon Quantum Dot/NiFe Layered Double-Hydroxide Composite as a Highly Efficient Electrocatalyst for Water Oxidation. ACS Appl. Mater. Interfaces 2014, 6, 7918-7925.

21. Zhu, X.; Tang, C.; Wang, H.-F.; Zhang, Q.; Yang, C.; Wei, F. Dual-Sized NiFe Layered Double Hydroxides in Situ Grown on Oxygen-Decorated Self-Dispersal Nanocarbon as Enhanced Water Oxidation Catalysts. J. Mater. Chem. A 2015, 3, 24540-24546.

22. Trotochaud, L.; Ranney, J. K.; Williams, K. N.; Boettcher, S. W. Solution-Cast Metal Oxide Thin Film Electrocatalysts for Oxygen Evolution. J. Am. Chem. Soc. 2012, 134, 1725317261. 
23. Rui, K.; Zhao, G. Q.; Chen, Y. P.; Lin, Y.; Zhou, Q.; Chen, J. Y.; Zhu, J. X.; Sun, W. P.; Huang, W.; Dou, S. X. DOI: 10.1002/adfm.201801554

24. Xie, J.; Zhang, X.; Zhang, H.; Zhang, J.; Li, S.; Wang, R.; Pan, B.; Xie, Y. Intralayered Ostwald Ripening to Ultrathin Nanomesh Catalyst with Robust Oxygen-Evolving Performance. Adv. Mater. 2017, 29.

25. Ye, G.; Gong, Y.; Lin, J.; Li, B.; He, Y.; Pantelides, S. T.; Zhou, W.; Vajtai, R.; Ajayan, P. M. Defects Engineered Monolayer $\mathrm{MoS}_{2}$ for Improved Hydrogen Evolution Reaction. Nano Lett. 2016, 16, 1097-1103.

26. Zhao, W.; Zhang, C.; Geng, F.; Zhuo, S.; Zhang, B. Nanoporous Hollow Transition Metal Chalcogenide Nanosheets Synthesized Via the Anion-Exchange Reaction of Metal Hydroxides with Chalcogenide Ions. ACS nano 2014, 8, 10909-10919.

27. Mazloomi, S.; Sulaiman, N. Influencing Factors of Water Electrolysis Electrical Efficiency. Renew. Sust. Energ. Rev. 2012, 16, 4257-4263.

28. Chen, J. Y.; Dang, L.; Liang, H.; Bi, W.; Gerken, J. B.; Jin, S.; Alp, E. E.; Stahl, S. S. Operando Analysis of $\mathrm{NiFe}$ and $\mathrm{Fe}$ Oxyhydroxide Electrocatalysts for Water Oxidation: Detection of $\mathrm{Fe}^{4+}$ by Mossbauer Spectroscopy. J. Am. Chem. Soc. 2015, 137, 15090-15093.

29. Dresp, S.; Luo, F.; Schmack, R.; Kühl, S.; Gliech, M.; Strasser, P. An Efficient Bifunctional Two-Component Catalyst for Oxygen Reduction and Oxygen Evolution in Reversible Fuel Cells, Electrolyzers and Rechargeable Air Electrodes. Energ. Environ. Sci. 2016, 9, 2020-2024.

30. Lu, Z.; Xu, W.; Zhu, W.; Yang, Q.; Lei, X.; Liu, J.; Li, Y.; Sun, X.; Duan, X. ThreeDimensional NiFe Layered Double Hydroxide Film for High-Efficiency Oxygen Evolution Reaction. Chem. Commun. 2014, 50, 6479-6482.

31. Li, Z.; Shao, M.; An, H.; Wang, Z.; Xu, S.; Wei, M.; Evans, D. G.; Duan, X. Fast Electrosynthesis of Fe-Containing Layered Double Hydroxide Arrays toward Highly Efficient Electrocatalytic Oxidation Reactions. Chem. Sci. 2015, 6, 6624-6631.

32. Lo, N.-C.; Chung, P.-C.; Chuang, W.-J.; Hsu, S. C.; Sun, I.-W.; Chen, P.-Y. Voltammetric Study and Electrodeposition of $\mathrm{Ni}(\mathrm{II}) / \mathrm{Fe}(\mathrm{II})$ in the Ionic Liquid 1-Butyl-1Methylpyrrolidinium Dicyanamide. J. Electrochem. Soc. 2016, 163, D9-D16.

33. Louie, M. W.; Bell, A. T. An Investigation of Thin-Film Ni-Fe Oxide Catalysts for the Electrochemical Evolution of Oxygen. J. Am. Chem. Soc. 2013, 135, 12329-12337.

34. Morales-Guio, C. G.; Mayer, M. T.; Yella, A.; Tilley, S. D.; Grätzel, M.; Hu, X. An Optically Transparent Iron Nickel Oxide Catalyst for Solar Water Splitting. J. Am. Chem. Soc. 2015, 137, 9927-9936.

35. Swierk, J. R.; Klaus, S.; Trotochaud, L.; Bell, A. T.; Tilley, T. D. Electrochemical Study of the Energetics of the Oxygen Evolution Reaction at Nickel Iron (Oxy) Hydroxide Catalysts. $J$. Phys. Chem. C 2015, 119, 19022-19029.

36. Trotochaud, L.; Young, S. L.; Ranney, J. K.; Boettcher, S. W. Nickel-Iron Oxyhydroxide Oxygen-Evolution Electrocatalysts: The Role of Intentional and Incidental Iron Incorporation. $J$. Am. Chem. Soc. 2014, 136, 6744-6753.

37. Zhang, D.; Sun, W.; Chen, Z.; Zhang, Y.; Luo, W.; Jiang, Y.; Dou, S. X. TwoDimensional Cobalt-/Nickel-Based Oxide Nanosheets for High-Performance Sodium and Lithium Storage. Chem. Eur. J. 2016, 22, 18060-18065.

38. Stevens, M. B.; Trang, C. D.; Enman, L. J.; Deng, J.; Boettcher, S. W. Reactive Fe-Sites in Ni/Fe (Oxy) Hydroxide Are Responsible for Exceptional Oxygen Electrocatalysis Activity. $J$. Am. Chem. Soc. 2017, 139, 11361-11364. 
39. Wark, S. E.; Hsia, C.-H.; Son, D. H. Effects of Ion Solvation and Volume Change of Reaction on the Equilibrium and Morphology in Cation-Exchange Reaction of Nanocrystals. $J$. Am. Chem. Soc. 2008, 130, 9550-9555.

40. Gong, M.; Li, Y.; Wang, H.; Liang, Y.; Wu, J. Z.; Zhou, J.; Wang, J.; Regier, T.; Wei, F.; Dai, H. An Advanced Ni-Fe Layered Double Hydroxide Electrocatalyst for Water Oxidation. $J$. Am. Chem. Soc. 2013, 135, 8452-8455.

41. Khan, A. I.; O’Hare, D. Intercalation Chemistry of Layered Double Hydroxides: Recent Developments and Applications. J. Mater. Chem. 2002, 12, 3191-3198.

42. Zhao, X.; Xu, S.; Wang, L.; Duan, X.; Zhang, F. Exchange-Biased $\mathrm{NiFe}_{2} \mathrm{O}_{4} / \mathrm{NiO}$ Nanocomposites Derived from NiFe-Layered Double Hydroxides as a Single Precursor. Nano Res. 2010, 3, 200-210.

43. Kong, X.; Zhang, C.; Hwang, S. Y.; Chen, Q.; Peng, Z. Free-Standing Holey Ni(OH) Nanosheets with Enhanced Activity for Water Oxidation. Small 2017, 13.

44. Xia, X.; Zhu, C.; Luo, J.; Zeng, Z.; Guan, C.; Ng, C. F.; Zhang, H.; Fan, H. J. Synthesis of Free-Standing Metal Sulfide Nanoarrays Via Anion Exchange Reaction and Their Electrochemical Energy Storage Application. small 2014, 10, 766-773.

45. Zhou, P.; Wang, Y.; Xie, C.; Chen, C.; Liu, H.; Chen, R.; Huo, J.; Wang, S. Acid-Etched Layered Double Hydroxides with Rich Defects for Enhancing the Oxygen Evolution Reaction. Chem. Commun. 2017, 53, 11778-11781.

46. Uelzen, T.; Müller, J. Wettability Enhancement by Rough Surfaces Generated by Thin Film Technology. Thin Solid Films 2003, 434, 311-315.

47. Wenzel, R. N. Resistance of Solid Surfaces to Wetting by Water. Ind. Eng. Chem. 1936, 28, 988-994.

48. Lu, Z.; Zhu, W.; Yu, X.; Zhang, H.; Li, Y.; Sun, X.; Wang, X.; Wang, H.; Wang, J.; Luo, J. Ultrahigh Hydrogen Evolution Performance of under-Water "Superaerophobic" $\mathrm{MoS}_{2}$ Nanostructured Electrodes. Adv. Mater. 2014, 26, 2683-2687.

49. Dong, B.; Li, M.; Chen, S.; Ding, D.; Wei, W.; Gao, G.; Ding, S. Formation of g-C $\mathrm{C}_{3} \mathrm{~N}_{4} @$ $\mathrm{Ni}(\mathrm{OH})_{2}$ Honeycomb Nanostructure and Asymmetric Supercapacitor with High Energy and Power Density. ACS Appl. Mater. Interfaces 2017, 9, 17890-17896.

50. Grossnickle, J.; Vlases, G.; Hoffman, A.; Melnik, P.; Milroy, R.; Tankut, A.; Velas, K. Particle and Recycling Control in Translation, Confinement, and Sustainment Upgrade. Phy. Plasmas 2010, 17, 032506.

51. Zeng, L.; Ren, W.; Zheng, J.; Wu, A.; Cui, P. Synthesis of Water-Soluble Feooh Nanospindles and Their Performance for Magnetic Resonance Imaging. Appl. Surf. Sci. 2012, 258, 2570-2575.

52. Baltrusaitis, J.; Cwiertny, D. M.; Grassian, V. H. Adsorption of Sulfur Dioxide on Hematite and Goethite Particle Surfaces. Phys. Chem. Chem. Phys. 2007, 9, 5542-5554.

53. Xiong, D.; Li, W.; Liu, L. Vertically Aligned Porous Nickel (II) Hydroxide Nanosheets Supported on Carbon Paper with Long-Term Oxygen Evolution Performance. Chem.-Asian J. 2017, 12, 543-551.

54. Wang, H.; Casalongue, H. S.; Liang, Y.; Dai, H. Ni(OH $)_{2}$ Nanoplates Grown on Graphene as Advanced Electrochemical Pseudocapacitor Materials. J. Am. Chem. Soc. 2010, 132, $7472-7477$.

55. Hu, C.-C.; Wu, Y.-R. Bipolar Performance of the Electroplated Iron-Nickel Deposits for Water Electrolysis. Mater. Chem. Phys. 2003, 82, 588-596. 
56. Singh, R.; Pandey, J.; Anitha, K. Preparation of Electrodeposited Thin Films of NickelIron Alloys on Mild Steel for Alkaline Water Electrolysis. Part I: Studies on Oxygen Evolution. Int. J. Hydrogen Energ. 1993, 18, 467-473.

57. Gong, M.; Dai, H. A Mini Review of NiFe-Based Materials as Highly Active Oxygen Evolution Reaction Electrocatalysts. Nano Res. 2015, 8, 23-39.

58. $\quad$ Li, N.; Bediako, D. K.; Hadt, R. G.; Hayes, D.; Kempa, T. J.; von Cube, F.; Bell, D. C.; Chen, L. X.; Nocera, D. G. Influence of Iron Doping on Tetravalent Nickel Content in Catalytic Oxygen Evolving Films. P. Natl. Acad. Sci. 2017, 114, 1486-1491.

59. Bhaumik, A.; Mukherjee, P.; Kumar, R. Triphase Catalysis over Titanium-Silicate Molecular Sieves under Solvent-Free Conditions: I. Direct Hydroxylation of Benzene. J. Catal. 1998, 178, 101-107.

60. Ling, C.; Huang, Y.; Liu, H.; Wang, S.; Fang, Z.; Ning, L. Mechanical Properties, Electronic Structures, and Potential Applications in Lithium Ion Batteries: A First-Principles Study toward SnSe 2 Nanotubes. J. Phys. Chem. C 2014, 118, 28291-28298.

61. Qi, J.; Zhang, W.; Xiang, R.; Liu, K.; Wang, H. Y.; Chen, M.; Han, Y.; Cao, R. Porous Nickel-Iron Oxide as a Highly Efficient Electrocatalyst for Oxygen Evolution Reaction. Adv. sci. 2015, 2. 


\section{Table of Contents Graphic}

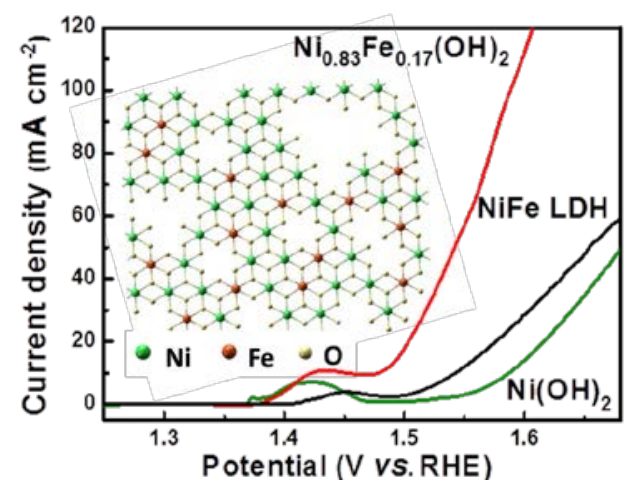




\section{Supporting Information}

\section{Active Site-Enriched Iron-Doped Nickel/Cobalt Hydroxide Nanosheets for Enhanced Oxygen \\ Evolution Reaction}

Qian Zhou ${ }^{a}$, Yaping Chen ${ }^{a}$, Guoqiang Zhao ${ }^{a}$, Yue Lin $^{b,{ }^{*}}$, Zhenwei Yu ${ }^{a}$, Xun Xu ${ }^{a, *}$, Xiaolin Wang ${ }^{a}$,

Hua Kun Liu ${ }^{a}$, Wenping Sun ${ }^{a,}$, Shi Xue Dou

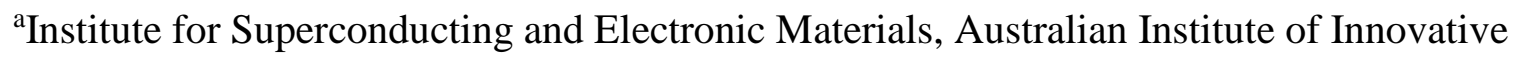

Materials, University of Wollongong, Wollongong, NSW 2522, Australia

Email: xun@uow.edu.au; wenping@uow.edu.au

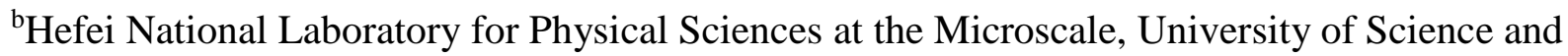

Technology of China, Hefei, Anhui 230026, P. R. China

Email: linyue@ustc.edu.cn 


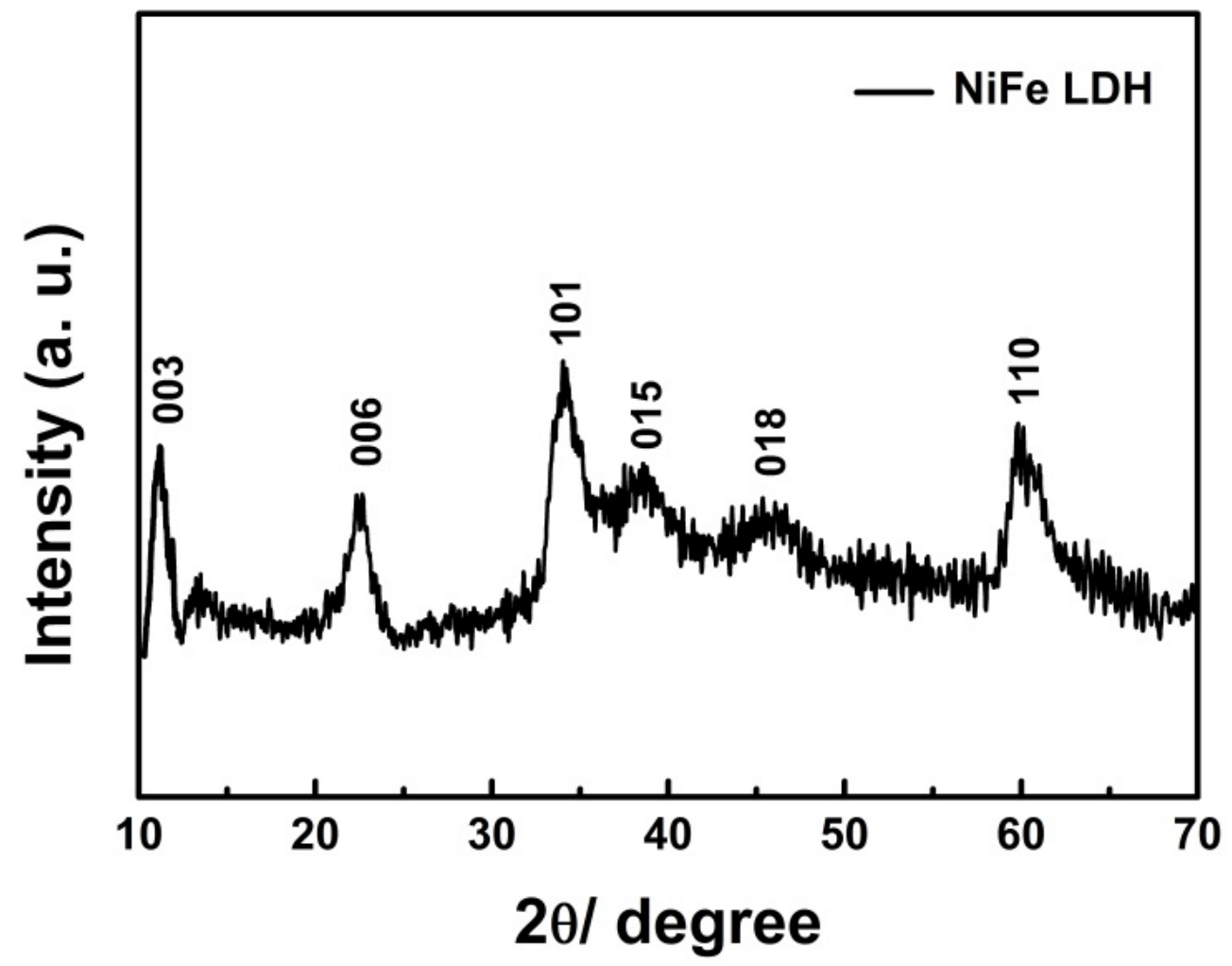

Figure S1. XRD pattern of NiFe LDH. 

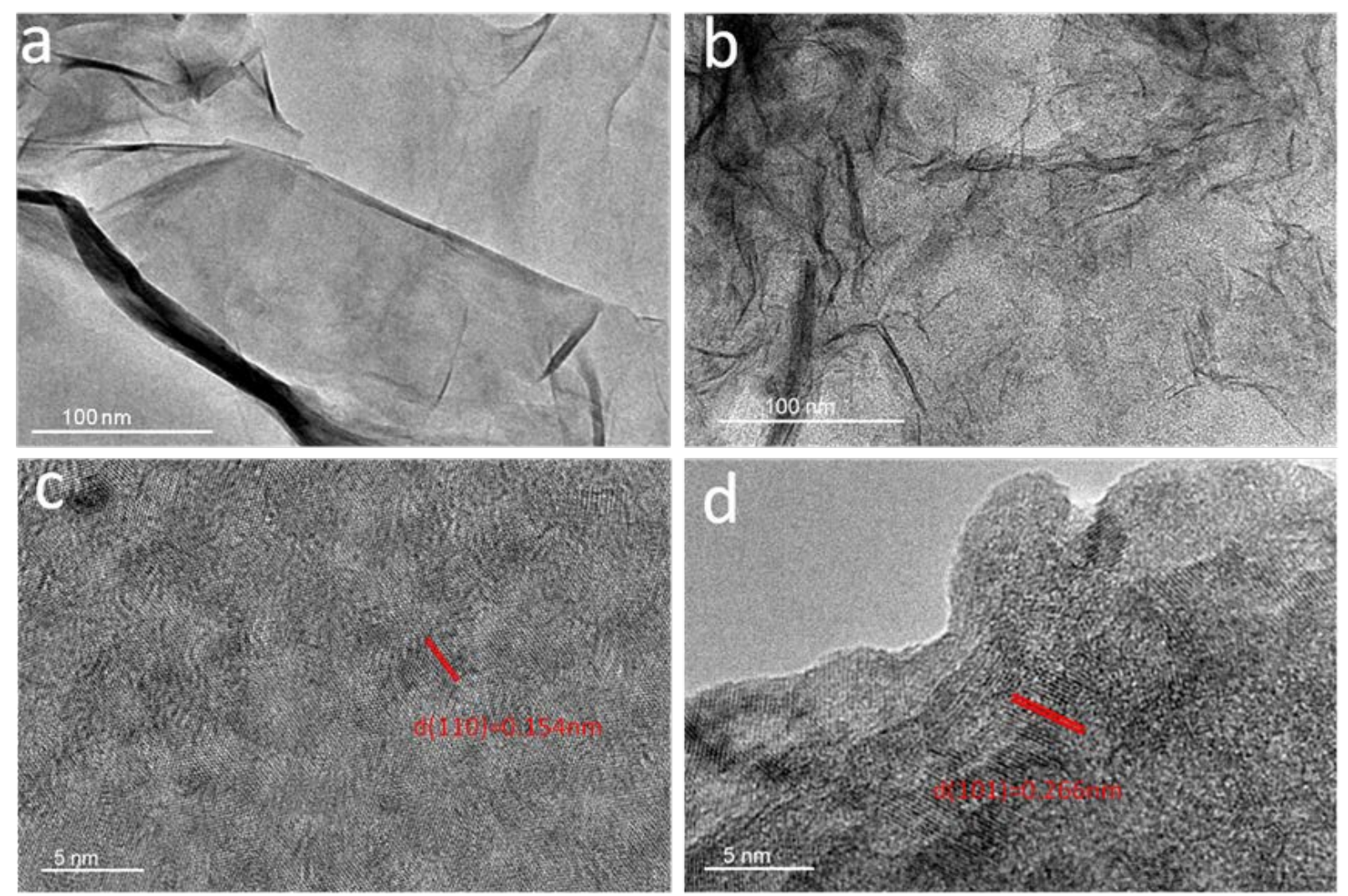

Figure S2. TEM images of pure $\mathrm{Ni}(\mathrm{OH})_{2}(\mathrm{a}, \mathrm{c})$ and $\mathrm{NiFe} \mathrm{LDH}(\mathrm{b}, \mathrm{d}) . \mathrm{Ni}(\mathrm{OH})_{2}$ and $\mathrm{NiFe} \mathrm{LDH}$ both exhibited smooth surface and flexible, transparent feature, suggesting fundamental characteristics in common of this kind of ultrathin sheet-like nanostructure. The lattice spacing of $0.154 \mathrm{~nm}$ and $0.25 \mathrm{~nm}$ is corresponding to $\mathrm{Ni}(\mathrm{OH})_{2}$ (110) plane and NiFe LDH (012) plane, respectively. 

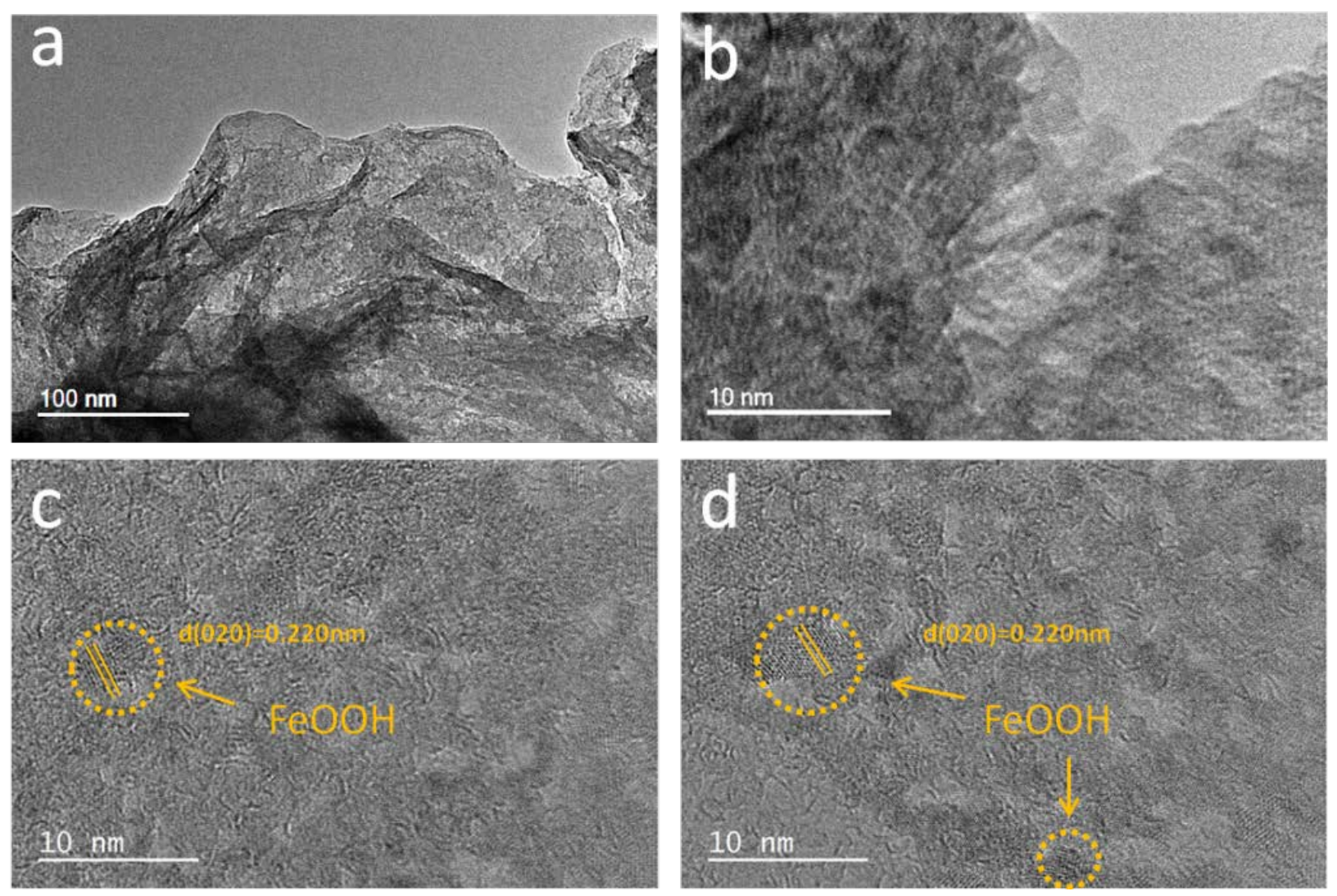

Figure S3. (a-d) TEM images of $\mathrm{Ni}_{0.83} \mathrm{Fe}_{0.17}(\mathrm{OH})_{2}$. After cation-exchange and chemical etching process, $\mathrm{Ni}_{0.83} \mathrm{Fe}_{0.17}(\mathrm{OH})_{2}$ nanosheets exhibits rough surface and distinct grain boundaries. The generation of $\mathrm{FeOOH}$ confirms the existence of reaction: $\mathrm{FeCl}_{3}+\mathrm{Ni}(\mathrm{OH})_{2} \rightarrow \mathrm{Fe}(\mathrm{OH})_{3}$ $(\mathrm{FeOOH})+\mathrm{NiCl}_{2}$ in this system. 

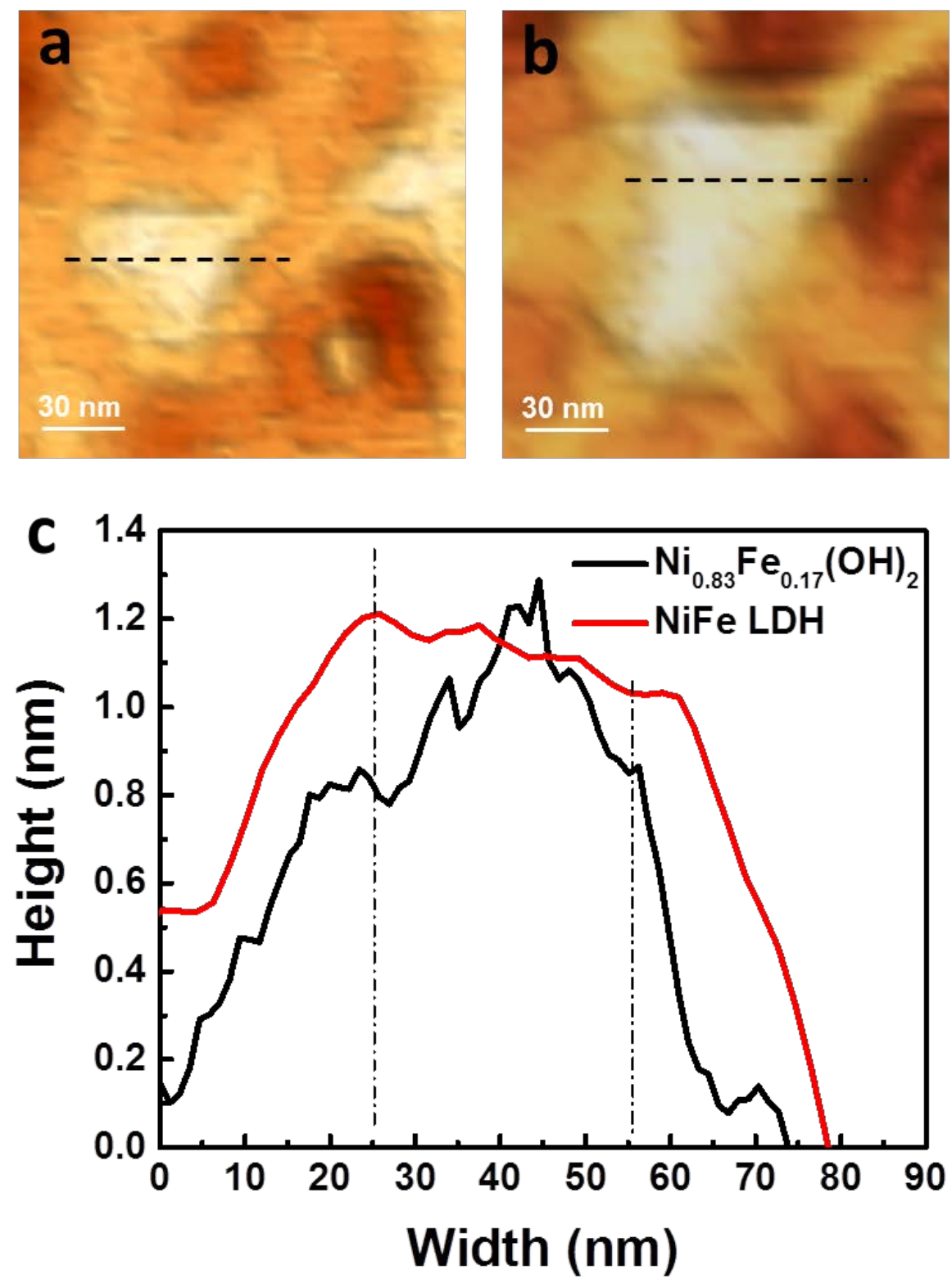

Figure S4. AFM images of (a) $\mathrm{Ni}_{0.83} \mathrm{Fe}_{0.17}(\mathrm{OH})_{2}$ and (b) $\mathrm{NiFe} \mathrm{LDH}$, (c) Cross-section line profile of the $\mathrm{Ni}_{0.83} \mathrm{Fe}_{0.17}(\mathrm{OH})_{2}$ and NiFe LDH ultrathin nanosheet shown in (a) and (b). 

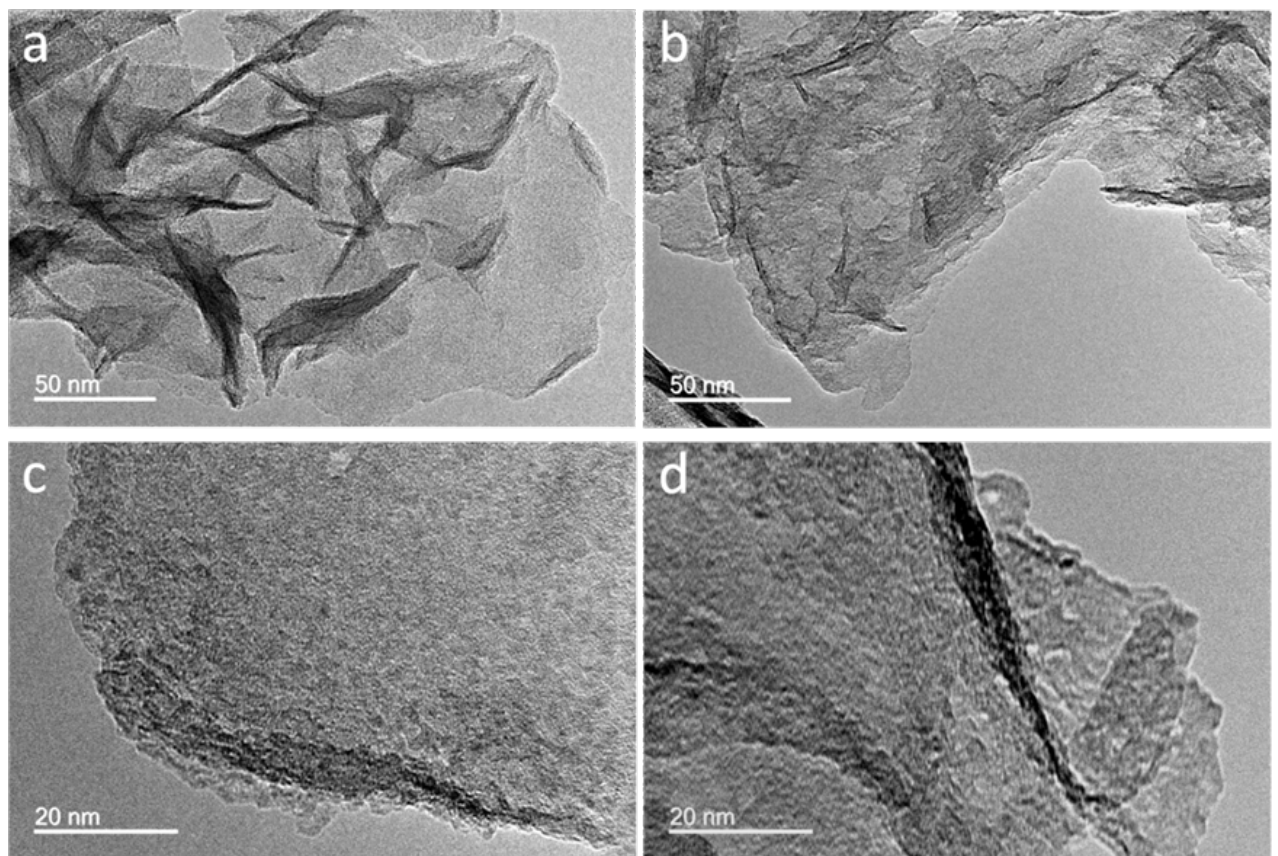

Figure S5. TEM images of $\mathrm{Ni}_{0.97} \mathrm{Fe}_{0.03}(\mathrm{OH})_{2}$ (a, c), $\mathrm{Ni}_{0.77} \mathrm{Fe}_{0.23}(\mathrm{OH})_{2}(\mathrm{~b}, \mathrm{~d})$. 


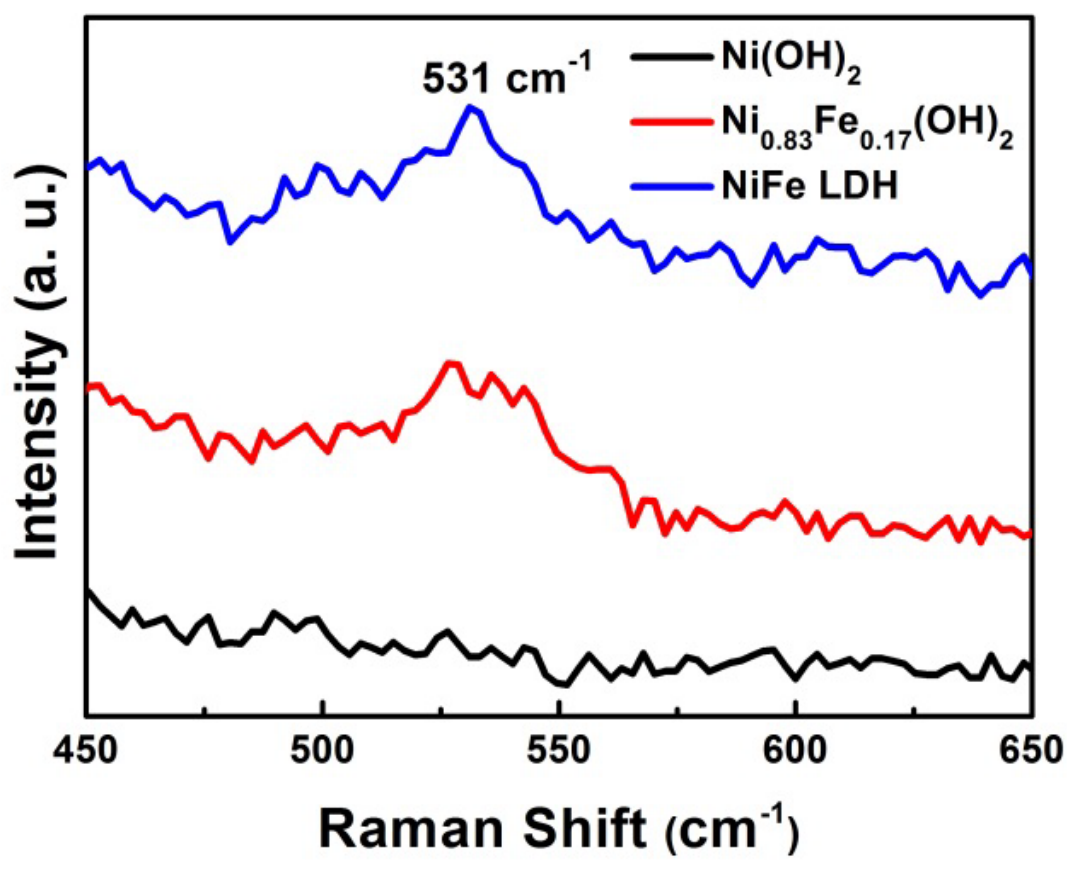

Figure S6. Raman spectrums of $\mathrm{Ni}(\mathrm{OH})_{2}, \mathrm{Ni}_{0.83} \mathrm{Fe}_{0.17}(\mathrm{OH})_{2}$ and $\mathrm{NiFe} \mathrm{LDH}$. 


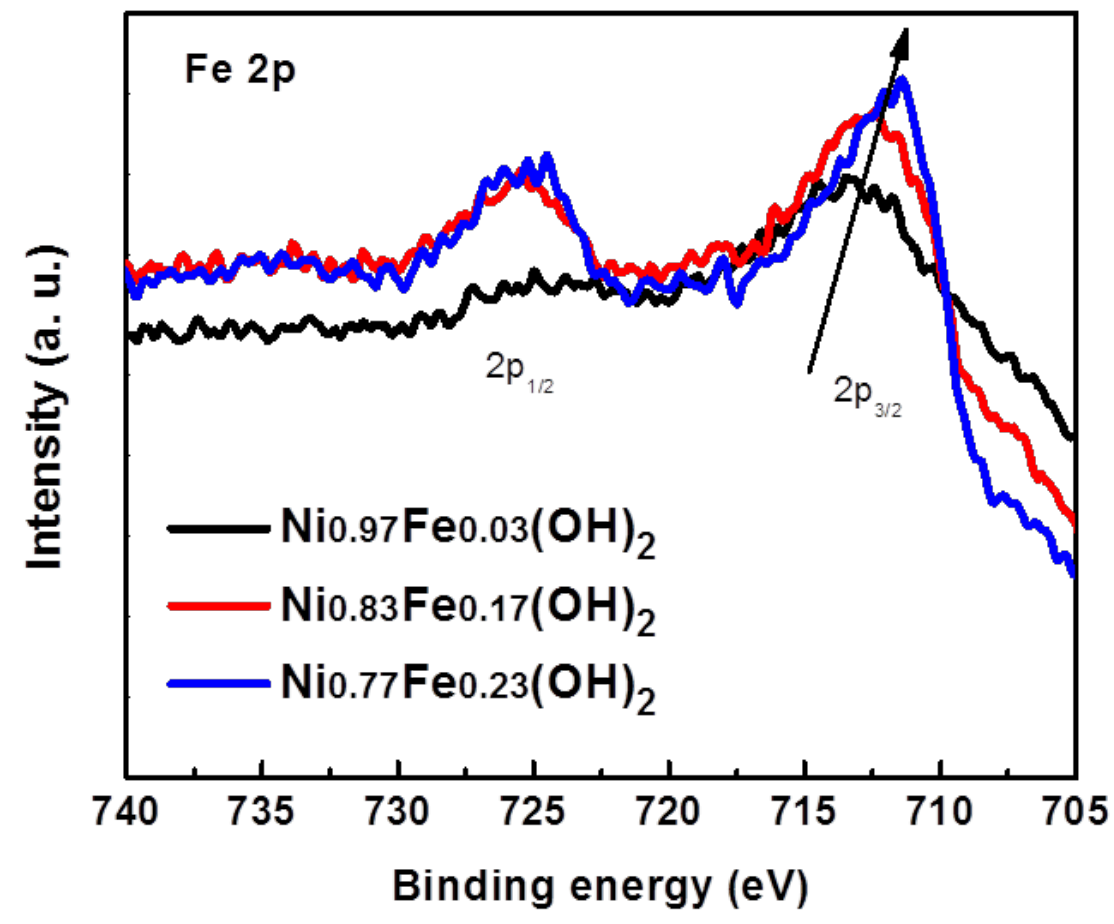

Figure S7. Fe 2p spectrum of $\mathrm{Ni}_{1-\mathrm{x}} \mathrm{Fe}_{\mathrm{x}}(\mathrm{OH})_{2}$ 

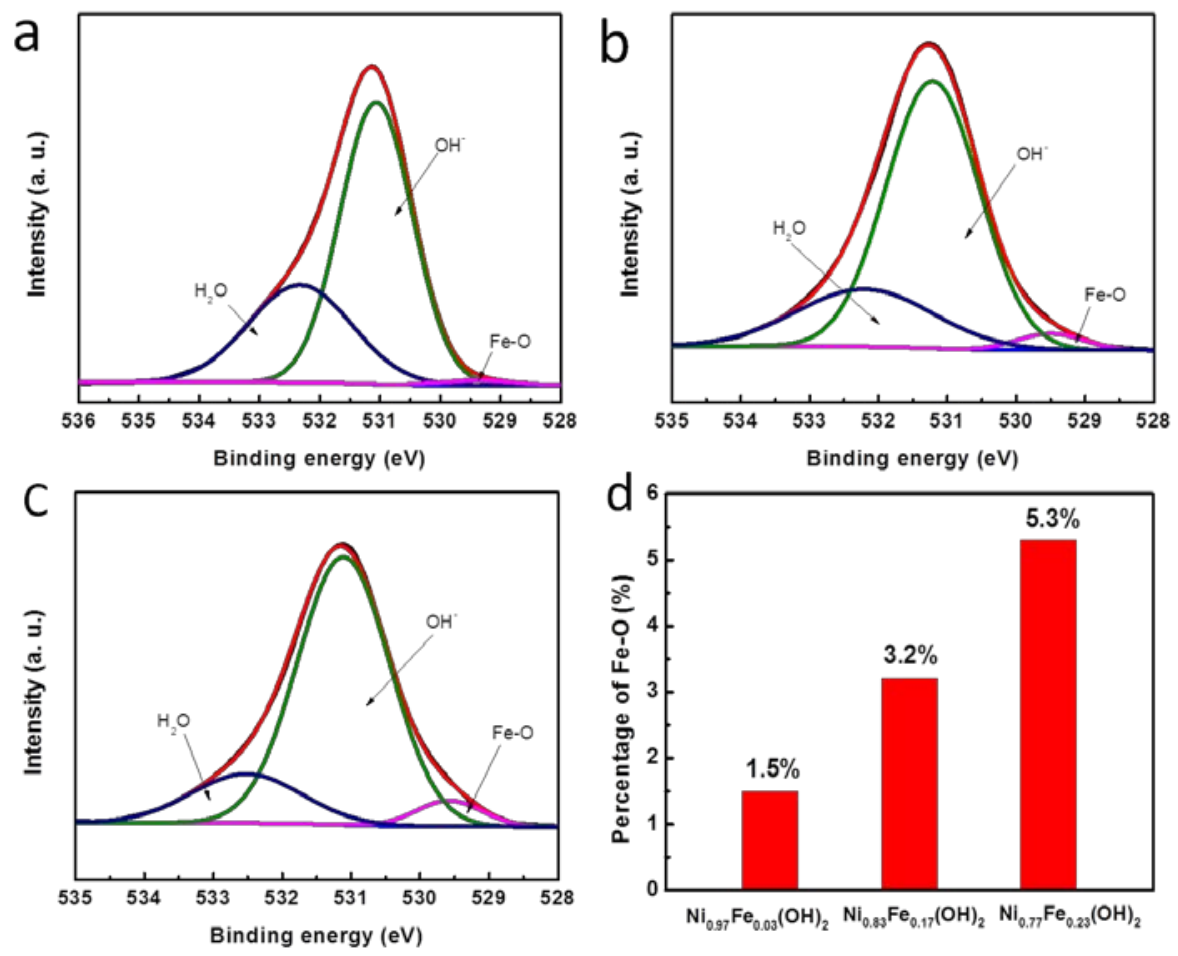

Figure S8. $\mathrm{O}$ 1s spectrum of $\mathrm{Ni}_{0.97} \mathrm{Fe}_{0.03}(\mathrm{OH})_{2}(\mathrm{a}), \mathrm{Ni}_{0.83} \mathrm{Fe}_{0.17}(\mathrm{OH})_{2}$ (b), $\mathrm{Ni}_{0.77} \mathrm{Fe}_{0.23}(\mathrm{OH})_{2}$ (c); (d) percentage of $\mathrm{Fe}-\mathrm{O}$ for $\mathrm{Ni}_{1-\mathrm{x}} \mathrm{Fe}_{\mathrm{x}}(\mathrm{OH})_{2}$. 


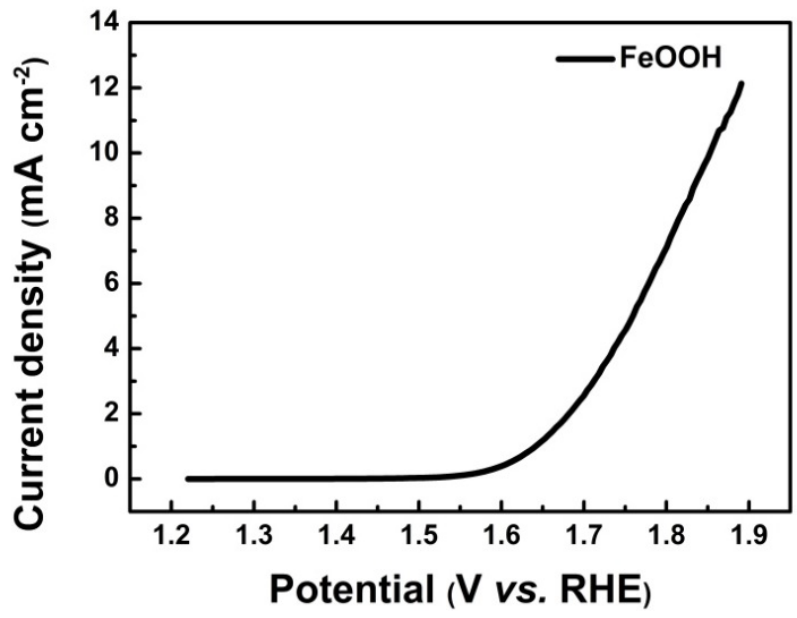

Figure S9. iR-corrected polarization curve of FeOOH measured at scan rate of $5 \mathrm{mV} \mathrm{s}^{-1}$ in $1 \mathrm{M}$ $\mathrm{KOH}$ solution. The overpotential of FeOOH at current density of $10 \mathrm{~mA} \mathrm{~cm}{ }^{-2}$ is about $620 \mathrm{mV}$. 

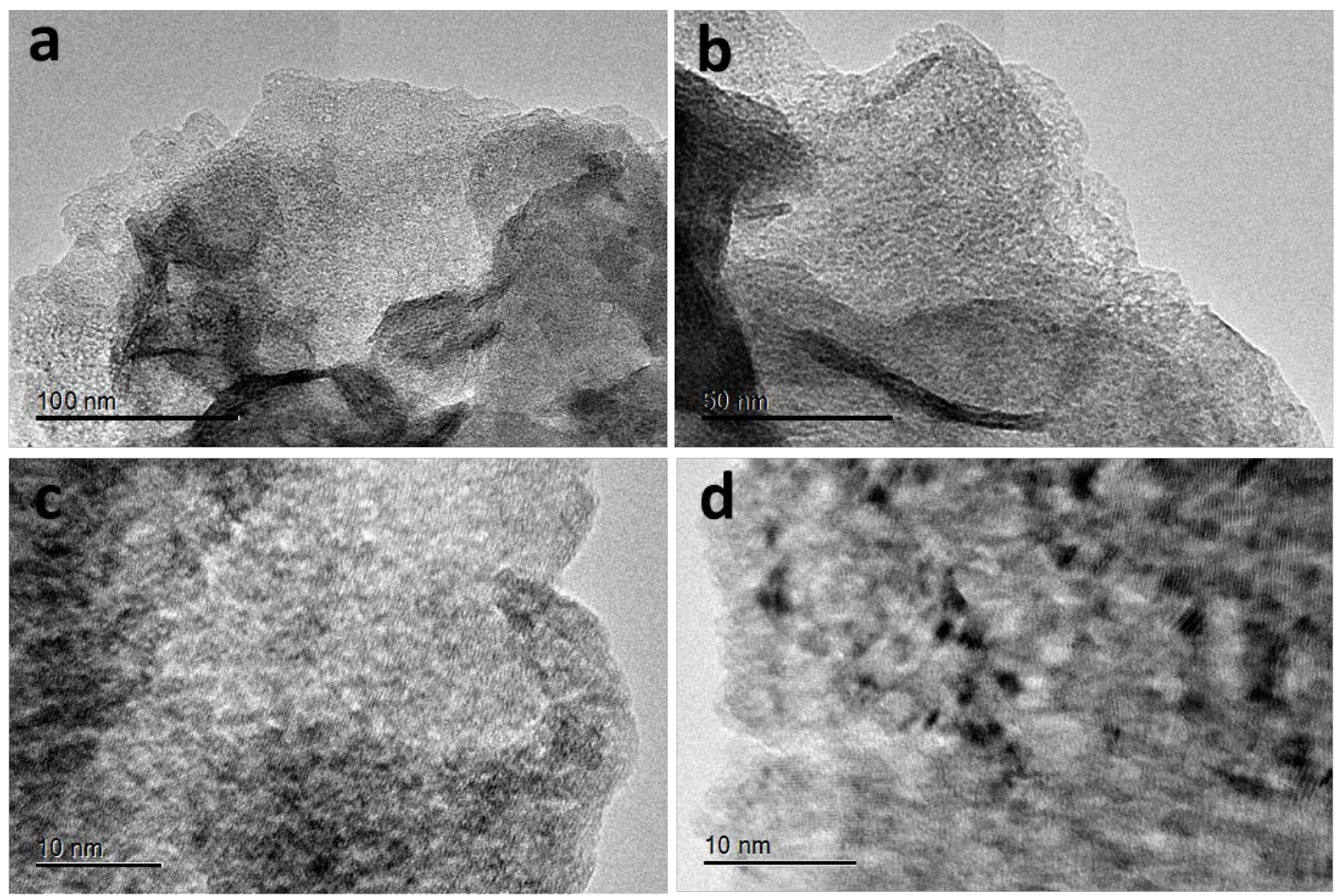

Figure S10. (a-d) TEM images of $\mathrm{Ni}_{0.97} \mathrm{Fe}_{0.03}(\mathrm{OH})_{2}$ after 200 cycles. 

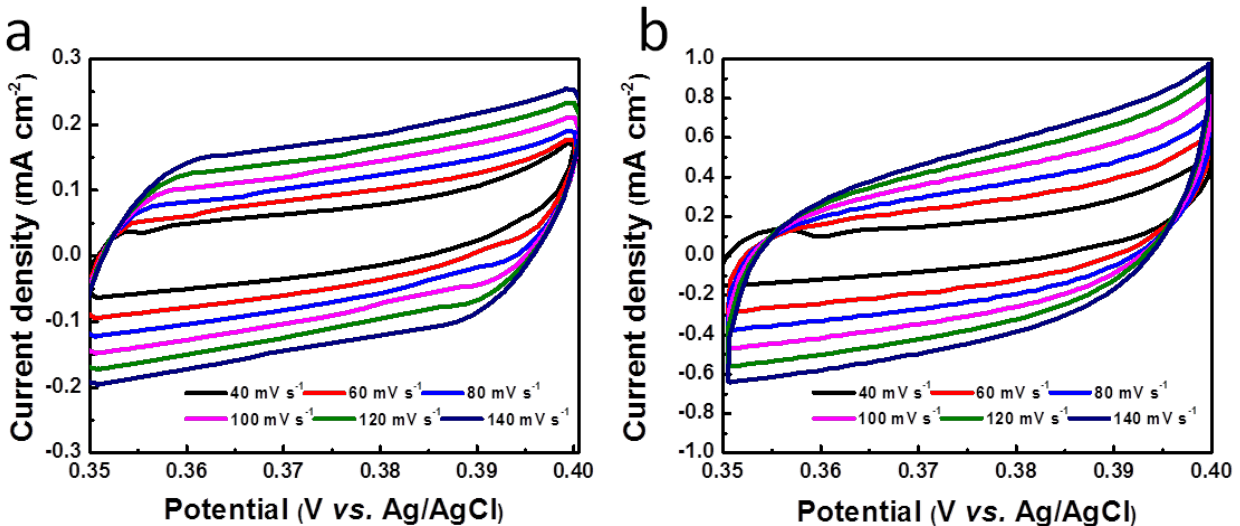

Figure S11. CV curves of (a) $\mathrm{NiFe} \mathrm{LDH}$ and (b) $\mathrm{Ni}_{0.83} \mathrm{Fe}_{0.17}(\mathrm{OH})_{2}$ electrode in $1 \mathrm{M} \mathrm{KOH}$ with different scan rates. 


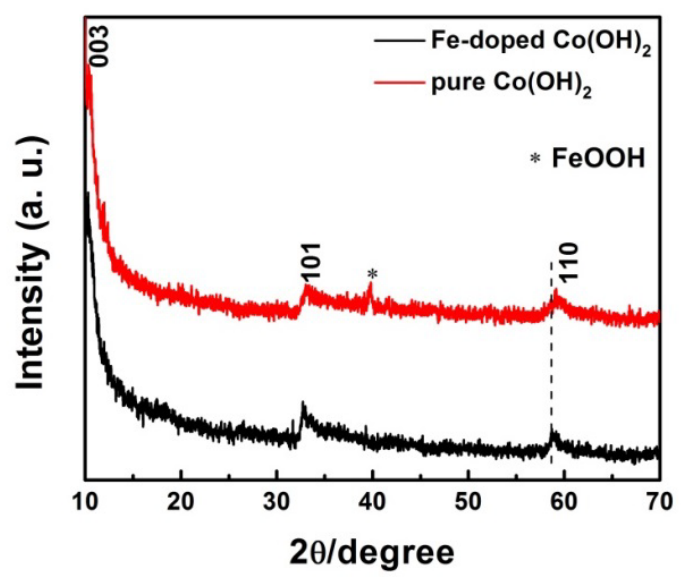

Figure S12. XRD pattern of $\mathrm{Co}(\mathrm{OH})_{2}$ and Fe-doped $\mathrm{Co}(\mathrm{OH})_{2}$. Fe-doped $\mathrm{Co}(\mathrm{OH})_{2}$ and $\mathrm{Co}(\mathrm{OH})_{2}$ both show peaks at around $10.5^{\circ}, 33.1^{\circ}$ and $59.0^{\circ}$ correspond to (003), (101) and (110) planes of typical $\alpha$-hydroxides, ${ }^{1}$ indicating the crystal structure of Fe-doped $\mathrm{Co}(\mathrm{OH})_{2}$ is maintained after cation exchange. It is noted that the (110) diffraction peak of Fe-doped $\mathrm{Co}(\mathrm{OH})_{2}$ shifts to higher degree as compared with $\mathrm{Co}(\mathrm{OH})_{2}$, which can also be attributed to the lattice shrinkage induced by the substitution of $\mathrm{Ni}^{2+}(65 \mathrm{pm})$ with smaller $\mathrm{Fe}^{3+}(55 \mathrm{pm})$. In addition, the peak at $39.8^{\circ}$ in curve of Fe-doped $\mathrm{Co}(\mathrm{OH})_{2}$, which can be indexed to FeOOH (JCPDS No. 26-0792) induced by chemical etching. 

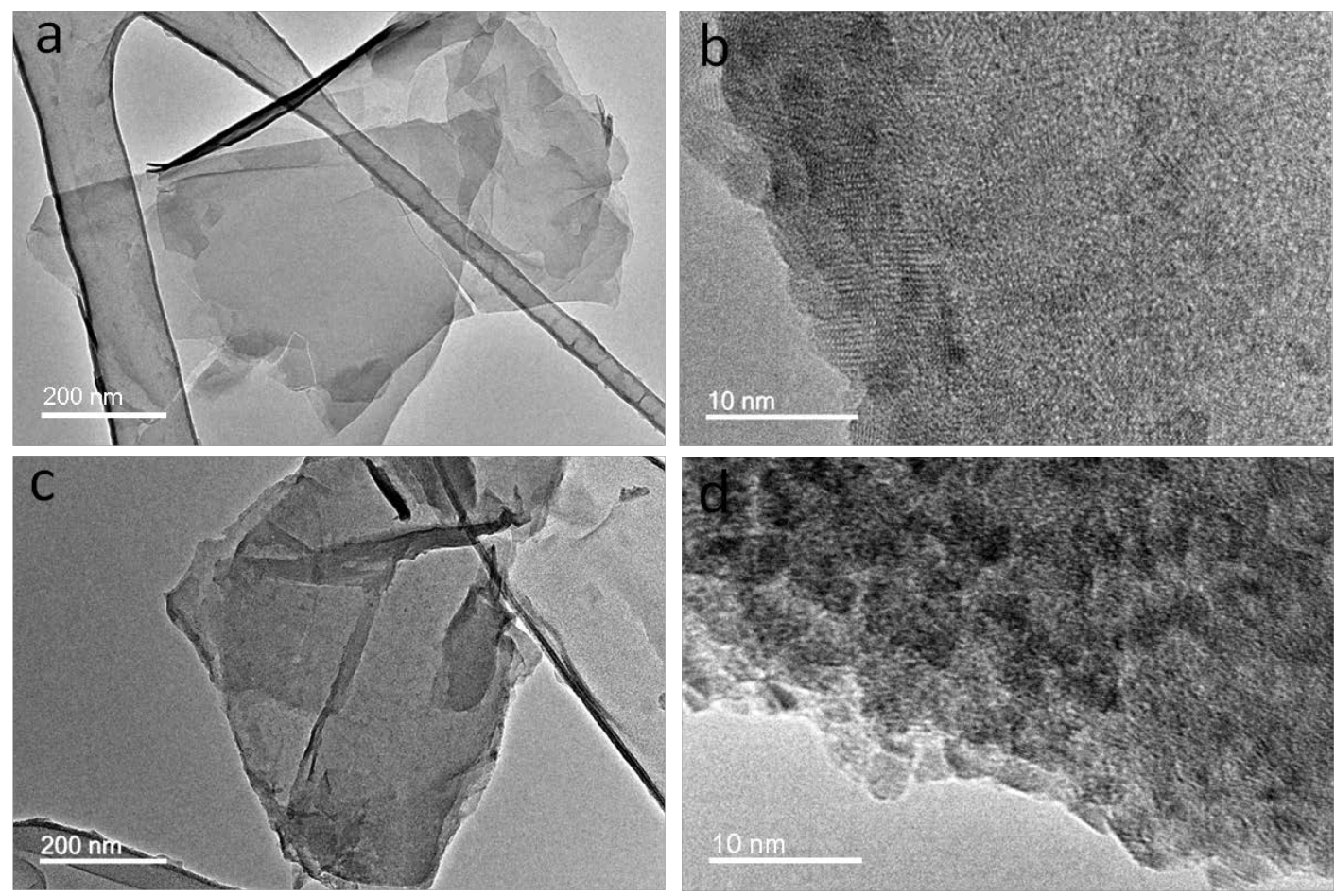

Figure S13. TEM images of pure $\mathrm{Co}(\mathrm{OH})_{2}(\mathrm{a}, \mathrm{b})$ and Fe-doped $\mathrm{Co}(\mathrm{OH})_{2}$ (c, d). 

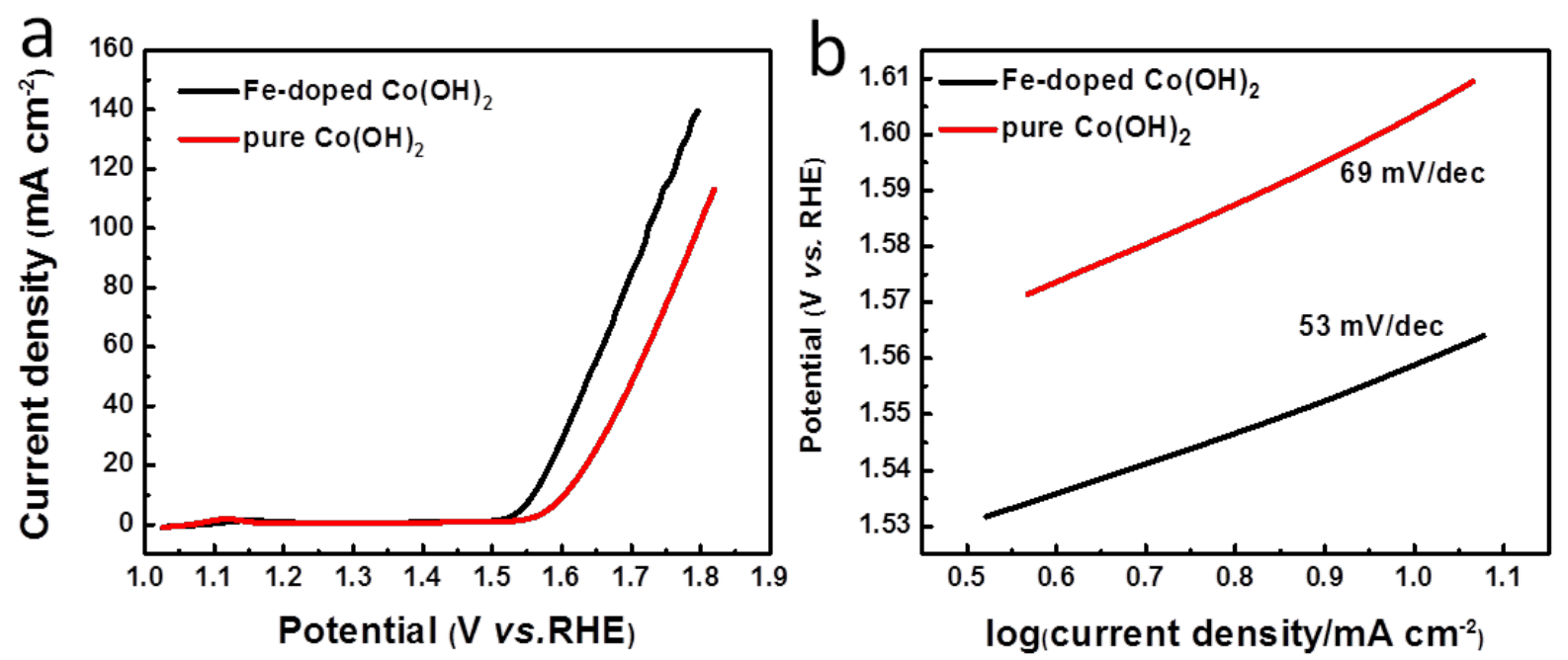

Figure S14. (a) iR-corrected polarization curves measured at scan rate of $5 \mathrm{mV} \mathrm{s}^{-1}$ in $1 \mathrm{M} \mathrm{KOH}$ solution, (b) tafel plots derived from LSV curves. 

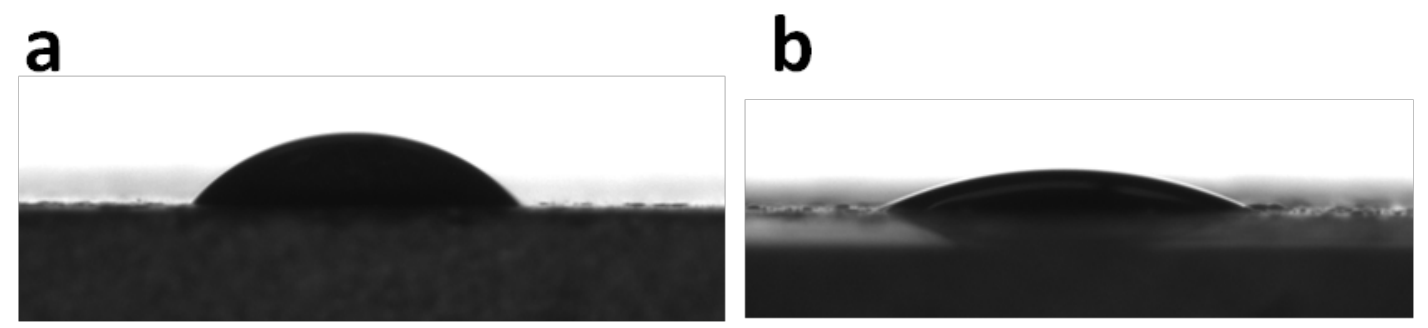

Figure S15. Contact angle measurements of (a) pure $\mathrm{Co}(\mathrm{OH})_{2}$ and (b) Fe-doped $\mathrm{Co}(\mathrm{OH})_{2}$. Fedoped $\mathrm{Co}(\mathrm{OH})_{2}$ with rough surface and distinct grain boundaries is much more hydrophilic with a contact angle of $26^{\circ}$, in contrast to $49^{\circ}$ for $\mathrm{Co}(\mathrm{OH})_{2}$, which importantly facilitated the affinity between the catalyst and electrolyte and enhanced the permeation of electrolyte ions. 
Table S1 OER performance comparison of some $\mathrm{Ni}(\mathrm{OH})_{2}$ and $\mathrm{NiF}$ LDH-based materials.

\begin{tabular}{|c|c|c|c|c|c|c|}
\hline Catalyst & Substrate & $\begin{array}{l}\text { Catalyst loading } \\
\left(\mu \mathrm{g} \mathrm{cm}^{-2}\right) / T h i n \\
\text { film thickness(nm) }\end{array}$ & Electrolyte & $\begin{array}{c}\begin{array}{c}\text { Overpotential } \\
(\mathrm{mV})\end{array} \\
\mathrm{j}=10 \mathrm{~mA} \mathrm{~cm}^{-2}\end{array}$ & $\begin{array}{l}\text { Tafel slope } \\
\left(\mathrm{mV} \text { dec }^{-1}\right)\end{array}$ & Ref. \\
\hline Holey $\beta$-Ni(OH $)_{2}$ & GC & 204 & $1.0 \mathrm{M} \mathrm{KOH}$ & 335 & 65 & 2 \\
\hline$\alpha-\mathrm{Ni}(\mathrm{OH})_{2}$ nanoparticles & GC & 142 & $1.0 \mathrm{M} \mathrm{KOH}$ & 299 & 53 & 3 \\
\hline Fe:Ni(OH $)_{2}$ film & $\mathrm{Au}$ & /30 & $1.0 \mathrm{M} \mathrm{KOH}$ & 280 & 40 & 4 \\
\hline NiFe LDH & GC & 70 & $1.0 \mathrm{M} \mathrm{KOH}$ & 347 & 67 & 5 \\
\hline NiFe LDH exfoliated & GC & 70 & $1.0 \mathrm{M} \mathrm{KOH}$ & 302 & 40 & 5 \\
\hline $\mathrm{NiFe} \mathrm{LDH}-\mathrm{MoO}_{4}^{2-}$ & GC & 280 & $1.0 \mathrm{M} \mathrm{KOH}$ & 280 & 40 & 6 \\
\hline \multicolumn{7}{|l|}{ /Ketjen black } \\
\hline NiFe LDH & HOPG & 444 & $1.0 \mathrm{M} \mathrm{KOH}$ & 280 & 47.6 & 7 \\
\hline NiFe LDH/CNT hybrid & CFP & 250 & $1.0 \mathrm{M} \mathrm{KOH}$ & 247 & 31 & 8 \\
\hline FeNi LDH & NF & 250 & $1.0 \mathrm{M} \mathrm{KOH}$ & 232 & 48 & 9 \\
\hline FeNi-rGO LDH hybrid & NF & 250 & $1.0 \mathrm{M} \mathrm{KOH}$ & 206 & 39 & 9 \\
\hline $\mathrm{Ni}-\mathrm{Fe} / 3 \mathrm{D}-\mathrm{ErGO}$ & $\mathrm{Au}$ & 140 & $1.0 \mathrm{M} \mathrm{KOH}$ & 259 & 33 & 10 \\
\hline $\mathrm{NiFe/RGO}$ & GC & 1000 & $1.0 \mathrm{M} \mathrm{KOH}$ & 245 & - & 11 \\
\hline NiFe LDH@HPGC & GC & 285 & $1.0 \mathrm{M} \mathrm{KOH}$ & 265 & 56 & 12 \\
\hline NiFe LDH-NS@DG & GC & 283 & $1.0 \mathrm{M} \mathrm{KOH}$ & 210 & 52 & 13 \\
\hline \multicolumn{7}{|l|}{ hybrid } \\
\hline $\mathrm{Ni}_{0.83} \mathrm{Fe}_{0.17}(\mathrm{OH})_{2}$ & GC & 204 & $1.0 \mathrm{M} \mathrm{KOH}$ & 245 & 61 & This work \\
\hline
\end{tabular}

\section{REFERENCES}

1. Li, R.; Hu, Z.; Shao, X.; Cheng, P.; Li, S.; Yu, W.; Lin, W.; Yuan, D. Large Scale Synthesis of NiCo Layered Double Hydroxides for Superior Asymmetric Electrochemical Capacitor. Sci. rep. 2016, 6, 18737.

2. Kong, X.; Zhang, C.; Hwang, S. Y.; Chen, Q.; Peng, Z. Free-Standing Holey Ni(OH $)_{2}$ Nanosheets with Enhanced Activity for Water Oxidation. Small 2017, 13.

3. Stern, L.-A.; Hu, X. Enhanced Oxygen Evolution Activity by $\mathrm{NiO}_{x}$ and $\mathrm{Ni}(\mathrm{OH})_{2}$ Nanoparticles. Faraday Discuss. 2015, 176, 363-379.

4. $\quad$ Klaus, S.; Cai, Y.; Louie, M. W.; Trotochaud, L.; Bell, A. T. Effects of Fe Electrolyte Impurities on $\mathrm{Ni}(\mathrm{OH})_{2} / \mathrm{NiOOH}$ Structure and Oxygen Evolution Activity. J. Phys. Chem. C 2015, 119, 7243-7254.

5. Song, F.; Hu, X. Exfoliation of Layered Double Hydroxides for Enhanced Oxygen Evolution Catalysis. Nat. Commun. 2014, 5. 
6. Han, N.; Zhao, F.; Li, Y. Ultrathin Nickel-Iron Layered Double Hydroxide Nanosheets Intercalated with Molybdate Anions for Electrocatalytic Water Oxidation. J. Mater. Chem. A 2015, 3, 16348-16353.

7. $\quad$ Hunter, B. M.; Blakemore, J. D.; Deimund, M.; Gray, H. B.; Winkler, J. R.; Müller, A. M. Highly Active Mixed-Metal Nanosheet Water Oxidation Catalysts Made by Pulsed-Laser Ablation in Liquids. J. Am. Chem. Soc. 2014, 136, 13118-13121.

8. $\quad$ Gong, M.; Li, Y.; Wang, H.; Liang, Y.; Wu, J. Z.; Zhou, J.; Wang, J.; Regier, T.; Wei, F.; Dai, H. An Advanced Ni-Fe Layered Double Hydroxide Electrocatalyst for Water Oxidation. $J$. Am. Chem. Soc. 2013, 135, 8452-8455.

9. $\quad$ Long, X.; Li, J.; Xiao, S.; Yan, K.; Wang, Z.; Chen, H.; Yang, S. A Strongly Coupled Graphene and FeNi Double Hydroxide Hybrid as an Excellent Electrocatalyst for the Oxygen Evolution Reaction. Angew. Chem. 2014, 126, 7714-7718.

10. Yu, X.; Zhang, M.; Yuan, W.; Shi, G. A High-Performance Three-Dimensional Ni-Fe Layered Double Hydroxide/Graphene Electrode for Water Oxidation. J. Mater. Chem. A 2015, 3, 6921-6928.

11. Youn, D. H.; Park, Y. B.; Kim, J. Y.; Magesh, G.; Jang, Y. J.; Lee, J. S. One-Pot Synthesis of NiFe Layered Double Hydroxide/Reduced Graphene Oxide Composite as an Efficient Electrocatalyst for Electrochemical and Photoelectrochemical Water Oxidation. J. Power Sources 2015, 294, 437-443.

12. Ni, Y.; Yao, L.; Wang, Y.; Liu, B.; Cao, M.; Hu, C. Construction of Hierarchically Porous Graphitized Carbon-Supported NiFe Layered Double Hydroxides with a Core-Shell Structure as an Enhanced Electrocatalyst for the Oxygen Evolution Reaction. Nanoscale 2017, 9 , 1159611604.

13. Jia, Y.; Zhang, L.; Gao, G.; Chen, H.; Wang, B.; Zhou, J.; Soo, M. T.; Hong, M.; Yan, X.; Qian, G. A Heterostructure Coupling of Exfoliated Ni-Fe Hydroxide Nanosheet and Defective Graphene as a Bifunctional Electrocatalyst for Overall Water Splitting. Adv. Mater. 2017, 29. 